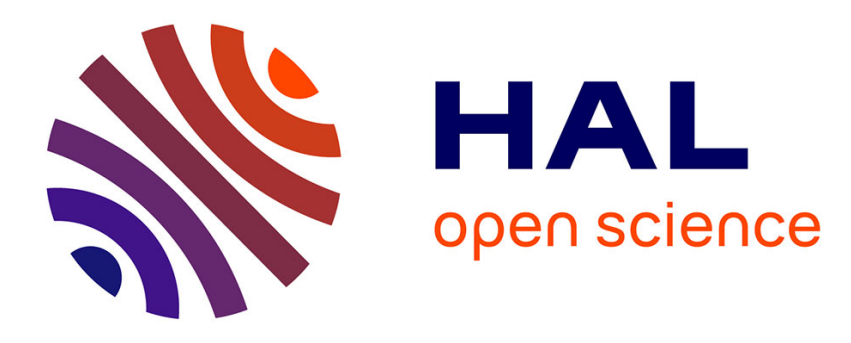

\title{
Degree structure as trope structure: a trope-based analysis of positive and comparative adjectives
}

\author{
Friederike Moltmann
}

\section{To cite this version:}

Friederike Moltmann. Degree structure as trope structure: a trope-based analysis of positive and comparative adjectives. Linguistics and Philosophy, 2009, 32 (1), pp.51-94. 10.1007/s10988-0099054-5 . hal-00535502

\author{
HAL Id: hal-00535502 \\ https://hal.science/hal-00535502
}

Submitted on 11 Nov 2010

HAL is a multi-disciplinary open access archive for the deposit and dissemination of scientific research documents, whether they are published or not. The documents may come from teaching and research institutions in France or abroad, or from public or private research centers.
L'archive ouverte pluridisciplinaire HAL, est destinée au dépôt et à la diffusion de documents scientifiques de niveau recherche, publiés ou non, émanant des établissements d'enseignement et de recherche français ou étrangers, des laboratoires publics ou privés. 


\title{
Degree structure as trope structure: a trope-based analysis of positive and comparative adjectives
}

\author{
Friederike Moltmann
}

Published online: 17 May 2009

(C) Springer Science+Business Media B.V. 2009

\begin{abstract}
This paper explores a novel analysis of adjectives in the comparative and the positive based on the notion of a trope, rather than the notion of a degree. Tropes are particularized properties, concrete manifestations of properties in individuals. The point of departure is that a sentence like 'John is happier than Mary' is intuitively equivalent to 'John's happiness exceeds Mary's happiness', a sentence that expresses a simple comparison between two tropes, John's happiness and Mary's happiness. The analysis received particular support from various parallels between adjectival constructions and corresponding adjective nominalizations which make reference to tropes.
\end{abstract}

Keywords Comparatives $\cdot$ Adjectives $\cdot$ Degrees $\cdot$ Tropes $\cdot$ Nominalizations

\section{Introduction}

In this paper, I will explore a novel analysis of positive and comparative adjectives as well as adjective nominalizations based on the notion of a trope. Tropes are particularized properties, concrete manifestations of a property in an individual. A trope is, for example, the redness of the box in front of me, which is the concrete manifestation of the property of being red in that box. The trope that is the redness of that box is an entity that, unlike redness as such, involves a very specific shade of red as well as a spatio-temporal location (it is spatio-temporally located just where the box is located while it is red). Thus, whereas redness is the universal that can be

F. Moltmann $(\bowtie)$

IHPST (Paris1/CNRS/ENS), 13 rue du Four, 75006 Paris, France

e-mail: fmoltmann@univ-paris1.fr 
instantiated by various particular objects, the redness of the box, like the box itself, is a particular: it is a particularized property. While tropes are not commonly used in natural language semantics, we have rather good intuitions about them, in particular since tropes are generally what we refer to with adjective nominalizations, such as the redness of the box, the wisdom of Socrates, or John's happiness.

Tropes (or accidents or modes) played an important role in ancient and medieval (Aristotelian) philosophy, where they were taken to be central to the semantics of adjectives. In that tradition, it was common to analyse Socrates is white as 'there is some whiteness (a trope) which inheres in Socrates', an analysis which went along with the view that the properties expressed by adjectives (such as the property of being white) are instantiated by tropes rather than individuals (even though adjectives are 'predicated of' individuals).

Tropes have also received renewed recent interest in metaphysics, though for purely philosophical reasons, such as the aim of construing properties in terms of particulars (tropes), rather than taking them to be abstract objects on their own.

The project of this paper is an exploration of the philosophical conception of tropes when applied to the semantics of adjectives and adjective nominalizations, especially in view of current semantic work on comparatives. Its aim is twofold:

[1] to show how the standard philosophical view of tropes itself must be refined and further developed in view of the range of linguistic data and generalizations, [2] to show that a trope-based analysis of adjectival constructions has a range of significant empirical and conceptual advantages over what has come to be the current standard approach to the semantics of positive and comparative adjectives, namely the degree-based approach. Unlike the degree-based approach, the trope-based approach accounts for adjective nominalizations. The semantic behaviour of adjective nominalizations in fact reflects a significant range of generalizations about positive and comparative adjectives, which is a strong indication that tropes rather than degrees are involved in the semantics of adjectives.

Degrees, abstract objects that form a total ordering, have come to play a central role in current analyses of comparatives and other constructions involving adjectives. On one such degree-based analysis, (1a) is analysed as in (1b) (Cresswell 1976):

(1) a. John is happier than Mary is.

b. The (maximal) degree to which John is happy exceeds the (maximal) degree to which Mary is happy.

Degrees are used not only for comparatives, but also for the analysis of adjectives in the positive form and various adjectival modifiers, such as completely, partially, almost, and slightly.

Degree-based analyses have shown considerable success in capturing various important semantic properties of adjectival constructions and generalizations about adjective modifiers. Nonetheless there are various respects in which degree-based analyses are fundamentally unsatisfactory. These include conceptual issues, such as 
the nature of degrees themselves, as well as a number of problematic empirical predictions made by degree-based accounts.

The point of departure of the trope-based analysis of comparatives is that a sentence like (1a) is intuitively equivalent to (2), where the happiness of John and the happiness of Mary both are trope-referring terms:

\section{(2) The happiness of John exceeds the happiness of Mary.}

One major advantage of the trope-based analysis of comparatives over degreebased analyses is that it makes use only of entities (tropes) which already play a role in the semantics of natural language, namely as referents of nominalizations such as John's happiness. The ability to apply adjectives like happy evidently goes along with the ability to refer to entities like John's happiness, but hardly with any knowledge about degrees of happiness. The trope-based analysis does not claim that natural language does not permit reference to degrees, but rather that natural language does not involve reference to degrees when there is insufficient evidence for it. The trope-based analysis at the same time aims to preserve various generalizations that have been established by using degrees. However, it construes degrees for those purposes in terms of tropes, rather than making degrees the point of departure for the semantics of adjectives. That is, degree structure is reconstructed as trope structure.

This paper does not only provide a reanalysis of the semantics of positive and comparative adjectives in terms of tropes; it also presents a range of new phenomena involving nominalizations and adjectival modifiers which provide specific evidence in favour of tropes and against degrees.

The general architecture of the semantics of adjectives and comparatives that I will propose is as follows: Adjectives are associated with 'comparative concepts', which are comparative trope relations, relations that order tropes according to the 'extent' to which they instantiate the adjectival content. These concepts underlie both the positive and the comparative form of the adjective. The comparative trope relations furthermore allow a reconstruction of degrees in terms of tropes, namely as equivalence classes of possible tropes.

\section{Some conceptual and empirical problems for degree-based analyses}

Let me start with the conceptual and empirical problems for degree-based analyses of adjectives. In most of the literature on the semantics of adjectives, it is left open what degrees actually are, as long as they come with the appropriate ordering. While Cresswell (1976) takes degrees to be equivalence classes of individuals, they are more often taken to be abstract objects of the same sort as numbers (von Stechow 1884; Pinkal 1989 among others). There are also approaches that take them to be 
intervals consisting of numbers (Kennedy 1999, 2001; Schwarzschild/Wilkinson 2002). In this paper, I will presuppose the most common, number- or interval-based version of the degree-based approach to comparatives. ${ }^{1}$

An apparent piece of evidence for the degree-based account is the possibility of overt degree-phrases, expressions which seem to spell out the degree supposedly involved in the meaning of the adjective, as in $(3 a, b)$ :

a. John is two meters tall.

b. John is two meters taller than Mary.

The distribution of degree-phrases, however, presents at the same time a serious problem for the degree-based account: degree-phrases are not possible with all adjectives that permit the comparative. The relevant generalization must make a distinction between degree-phrase modifiers of the positive form of adjectives, as in (3a), which I will call simple degree-phrases, and so-called differential degree phrases as in (3b), which modify the comparative. The generalization in question seems to be the following (cf. Schwarzschild 2005). Differential degree phrases as in (3a) are possible with any adjective associated with an established measurement scale. Simple degree phrases as in (3b), by contrast, are subject to certain general as well as idiosyncratic lexical restrictions. First, simple degree phrases are impossible with negative adjectives (* two meters small / narrow / short) (Kennedy 1999, 2001) and with excessives (* two meters enormous / huge). Second, simple degree-phrases are impossible even with certain adjectives associated with an established measurement scale, and whether they are possible seems to vary from language to language (for example English two kilos heavy is bad, but the German equivalent zwei Kilo schwer is fine) (cf. Schwarzschild 2005). Thus, a semantic analysis of degree phrases has to account both for the general difference between simple and differential degree phrases mentioned above and for the possibility of idiosyncratic lexical restrictions imposed by adjectives associated with a measurement scale. Moreover, the analysis needs to account for the fact that the majority of adjectives allowing for the comparative (beautiful, white, soft, strange...) do not allow for degree phrases even in the comparative construction.

What properties should degrees have? First of all, they are to come with a (total) ordering. For that purpose, they might be taken to just be numbers or intervals. As

\footnotetext{
1 Taking degrees for the purpose of the semantic analysis of comparatives to be equivalence classes of individuals appears to involve a circularity. The equivalence classes themselves will have to be defined by using the equative: two individuals $x$ and $y$ are in an equivalence class with respect to a property $P$ if $x$ is as $P$ as $y$. But then such a definition already presupposes the semantics of the equative 'is as $P$ as'. However, an analysis of the comparative need not provide an analysis of the comparative relation itself (cf. Klein 1991). In fact, the analysis in this paper will also take primitive comparative relations to underlie the semantics of adjectives, though they will order tropes rather than individuals.

There is another problem with the identification of degrees with equivalence classes of individuals, however. This is that the ordering cannot be read off such equivalence classes themselves, unlike with degrees conceived of as numbers. To determine whether the relation 'greater-than' or its converse holds between two equivalence classes, the comparative relation as such needs to be applied to representatives of those equivalence classes.
} 
Kennedy (1999), points out, however, taking degrees to be numbers is not enough if the aim is also to explain incommensurability in cases of comparative subdeletion, as in (4a), as well as its absence in cases like (4b):

(4) a. \# John is taller than Mary is beautiful.

b. The table is wider than the sofa is long.

What is needed in addition to a numerical representation is a type or dimension specifying whether the scale in question is one of spatial extension, weight, beauty, or whatever. In (4b), the types or dimensions are the same (linear spatial extension), whereas in (4a) they are different (height vs. beauty). Kennedy does not tell us how dimensions are to be conceived; they are closely linked to the meaning of the adjective, but different adjectives may obviously share a dimension. Also a dimension cannot just be a set of degrees: the same set of degrees may easily make up different dimensions. We will later see that the trope-based analysis provides a straightforward account of the restrictions on comparative subdeletion.

One major conceptual problem the degree-based approach faces is this: how can it be decided what objects to choose as the degrees in question? It is quite obvious that there are no good reasons to prefer any particular system of numbers over any other to represent a given scale of degrees. Even when a comparative involves an adjective that has a measure system associated with it, there is no reason to choose that system, when no explicit reference is made to it, rather than any other system the speaker may be familiar with. The choice of a measure system thus is, within limits, arbitrary in cases when an established measure system exists. The choice of any particular scale of numbers would be entirely arbitrary in cases of adjectives not associated with a measure system (beautiful, white etc).

The problem of the indeterminacy of the right choice of a system of objects to represent degrees is part of a more general problem, one in fact familiar from the philosophy of mathematics. In the philosophy of mathematics, the problem is trying to justify the choice of one set-theoretical construal of numbers over another: we know that numbers have certain properties and stand in certain relations to each other, but we have no way of knowing whether, for example, 2 is actually the set $\{\{0\}\}$ or $\{0,\{0\}\}$ (Benacerraf 1965). Similarly, degrees have certain properties, such as standing in certain relations, being associated with entities (relative to a dimension), but any additional properties such as being ' 1 ' as opposed to ' 100 ' would be enforced artificially by the choice of a measure system alone.

The problem in the philosophy of mathematics is generally considered a fundamental one, having lead to structuralist views and denials of the reality of numbers. In the case of the semantics of adjectives, by contrast, there appears to be a straightforward way of avoiding this kind of problem, and that is by using tropes (or entities constructed from tropes) instead of degrees.

Natural language does display terms making reference to degrees, such as the degree of John's happiness. I will later argue that such terms also involve reference to a trope of some sort, namely a degree trope. A degree trope is an entity that can 
be characterized in terms of its qualitative identity to other degree tropes as well as its bearer, but that is not to be identified with a number or other kind of abstract object.

A somewhat related problem to the one of the semanticist's choice of appropriate degree objects is for the language user to have cognitive access to what he is saying when apparent reference to a degree is made. If a speaker is not able to spell out what degree exactly is involved in the semantic structure of a comparative sentence, how can she actually know what she is saying? This is the meaning-intention problem that Schiffer (1987) raised in the context of modes of presentations when used as implicit arguments in attitude reports. It is a problem that routinely arises if the semanticist posits implicit abstract entities as part of the semantic structure of a sentence which a speaker may not be able to make explicit. Of course, for comparatives (as elsewhere) the meaning-intention problem does not arise if comparatives involve simply quantification over degrees, as in (1a). However, there are cases when reference to particular degrees would take place, for example in (5):

Mary is so happy!

In (5), so refers to a degree of happiness. The meaning-intention problem arising here is that the speaker would not have any clue as to what the abstract degree object is he makes reference to with the utterance of so.

One likely response to the meaning-intention problem, coming from within the Montagovian tradition, is that the task of semantics is simply to account for truth conditions, allowing for some degree of arbitrariness of the choice of objects in the model. I think that there are not only good reasons to impose general conditions on cognitive adequacy on a semantic analysis, but also in general the choice of one kind of object over another leads to different empirical predictions, for example concerning the acceptability of different classes of predicates with those objects. The empirical data in general favour tropes over any arbitrary or non-arbitrary choice of abstract objects.

Another conceptual problem for degree-based approaches concerns the ordering represented by the degrees. Assigning degrees to entities presupposes that the entities are ordered in the relevant respect. The respect-related ordering among the entities is prior to the ordering among the degrees. This then raises the question of why the adjective can not be taken to express the former ordering rather than the latter, which is precisely what the trope-based analysis aims to do.

\section{The trope-based analysis}

\subsection{Ontological properties of tropes}

Let us start by clarifying our intuitions about tropes, such as the trope that is John's happiness. John's happiness is the very particular way in which the property of being happy manifests itself in John; it consists in all there is about John that 
constitutes his happiness; it is the concrete manifestation of happiness in John. It is in that sense that John's happiness is a 'particularized property' or trope. ${ }^{2,3}$

John's happiness is particular to John, just as Mary's happiness is particular to Mary. That is, a trope is particular to its bearer.

John's happiness is similar to, but distinct from, Mary's happiness even if John and Mary are equally happy. Thus, John's happiness cannot just be a degree, a degree of happiness.

But perhaps John's happiness is just a more specific property than the general property of being happy. As such it presumably is still distinct from Mary's happiness, because it is unlikely that two people are happy in just the same way. But suppose the box is exactly the same shade of red as the table. Then the following sentence seems true, apparently expressing the identity of two more specific shades of redness:

(7) The redness of the box is the same as the redness of the table.

There is reason, however, not to take the same as in (7) to express numerical identity between two specific properties of redness, but rather qualitative identity (exact similarity) between tropes. ${ }^{4}$ Properties are abstract in the sense that they are not perceivable, they are not causally efficient, and they are not located in space and time. Tropes are concrete, at least if their bearer is concrete. They act as objects of perception and as relata of causal relations. Moreover, tropes are spatio-temporally located wherever their bearer is located. For example, John's happiness or the apple's redness may have been observed (object of perception), may have surprised (causal role), and may have lasted very long (temporal duration). Being objects of perception, relata of causal relations, and located in space and time are all properties that abstract objects such as degrees and properties cannot have, at least on most philosophers' views. Tropes are concrete entities (at least if their bearer is concrete), whereas degrees and properties are abstract, in the three senses of abstract.

There is another sense in which tropes are concrete: unlike properties, tropes must be maximally specific and determinate. Unlike redness itself, which is unspecific as to any particular shade of redness, the redness of the box is maximally specific: it involves one very specific shade of the color. Moreover, unlike happiness as such, which can manifest itself in various ways, John's happiness involves one particular manifestation, namely all there is about John that constitute his happiness. Tropes are maximally specific and determinate because they are entities in the

\footnotetext{
2 The term 'trope', a somewhat misleading term, has been introduced by Williams (1953). Other terms are 'particularized property', 'concrete property manifestation', 'abstract particular', 'case', 'accident', 'mode', and 'moment'.

3 The philosophical literature on tropes, ancient and modern, generally gives examples of tropes using nominalizations like John's happiness. Some of the literature also explicitly claims that nominalizations like John's happiness refer to tropes (Strawson 1959; Woltersdorff 1970; Moltmann 2004). Bacon (1995), by contrast, prefers to take gerunds like John's being happy as good cases of trope-referring terms, but see the discussion later in this section.

${ }^{4}$ In some contexts, same does not seem to express qualitative identity, for example in identity statements such as John is the same man as my teacher. But qualitative identity, contextually restricted, is what is arguably also expressed in John drives the same car as Mary.
} 
world: the world does not contain unspecific or determinable entities. In general the tropes that adjective nominalizations refer to are more specific than the properties expressed by the adjective used to refer to them. The reason is that the properties expressed by adjectives of natural language in general are not natural or sparse properties, that is, roughly, maximally specific and determinate properties. Tropes actually need not be instances of natural properties. But they must be composed of or grounded in instances of natural properties.

This groundedness of tropes, as I will call it, is well reflected in our linguistic intuitions about adjective nominalizations. It is reflected, in particular, in the way predicates of description and evaluation may apply to the entities in question: tropes can be described and evaluated with regard to the particular way in which they manifest a property:

a. John described Mary's beauty.

b. John admires Mary's beauty.

Tropes differ in that respect from abstract objects like facts or states (the referents of gerunds, like Mary's being beautiful or the state of Mary's being beautiful). Facts and states are not grounded: they just consist in the holding of a property of an object, without involving any particular way in which the property manifests itself in the object. Thus, they cannot be described or evaluated with regard to the particular way in which the property manifests itself (Moltmann 2007):

(9) a. ?? John described Mary's being beautiful.

b. ?? John admires Mary's being beautiful.

This difference between tropes and states is also reflected in the applicability of predicates of comparison, comparing entities with respect to their intrinsic properties, such as the predicates compare or exceed. John's happiness can exceed Mary's happiness because it is the particular way happiness manifests itself in John. John's happiness differs thus from the state of John's being happy which, being constituted only by John and by the unspecific property of being happy, cannot 'exceed' Mary's being happy. Similarly, it is hardly possible to compare John's being happy to Mary's being happy; though comparing John's happiness to Mary's happiness is unproblematic.

Tropes are not states. Tropes involve a particular way the property manifests itself in the individual. States, by contrast, only involve the holding of the property of the individual and nothing else; states are nothing but the holding of a property of an individual. Thus, a statue's beauty will involve all the particular properties of shape, colour, and so on that the statue instantiates. A state, by contrast, will be individuated only by whatever property is expressed by the predicate in question, however unspecific and indeterminate. States, therefore, are not grounded.

The groundedness of tropes consists in that tropes need to be composed, in some way, of instances of what are called natural or sparse properties, properties that are 
considered indispensable for a full description of the world, that are fully specific and determinate. ${ }^{5}$ We can thus state the condition of groundedness as follows:

(10) The Groundedness of Tropes

Tropes (as referents of adjective nominalizations) are composed of or based on instances of fully specific, determinate properties.

Most of the contemporary philosophical literature on tropes tacitly restricts its attention to tropes that are instances of sparse properties without taking into consideration the range of abundant properties that natural language predicates express.

Concerning the relation between tropes and properties, a very common view is that tropes as particulars can replace properties as universals. More precisely, properties can be identified with sets of resembling tropes (Williams 1953; Campbell 1990; Bacon 1995). ${ }^{6}$ For example, all redness tropes resemble each other and thus the property of being red can be identified with a set of resembling tropes. The possibility of reducing properties to tropes is in fact considered a major advantage of tropes: tropes allow dispensing with properties as abstract objects (universals), and instead allow a view of properties as concrete particulars. This way of dispensing with universals is sometimes called trope nominalism.

Natural properties, on such a view, are identified with sets of exactly resembling tropes. Non-natural properties or abundant properties, properties as expressed by natural language predicates, can be identified only with sets of tropes standing in a weaker relation of resemblance to each other (Campbell 1990). Thus, the set of redness tropes will include tropes of different shades of redness. Both exact resemblance and the weaker notions of resemblance must be equivalence relations (that is, transitive, symmetric, and reflexive) to yield sets of tropes constituting properties.

Trope nominalism assigns co-extensional predicates that express different properties different sets of resembling tropes as long as the predicates have a nonempty extension. Thus if all red things happen to be soft and vice versa, the properties of being red and of being soft will still be distinct, because a redness trope is a different trope from a softness trope. Trope nominalism will, however, identify properties that are true of no objects. The identification of properties with empty extensions can be avoided by identifying properties with functions from indices (world-time pairs) to sets of possible tropes; such a function will map each worldtime pair to a set of possible tropes that exist in that world at that time. Of course, admitting possibilia such as possible worlds and possible tropes is not a philosophical view every trope nominalist is willing to accept. However, there are a number of phenomena involving the semantics of adjectives for which the use of possible tropes is indispensable anyway, as we will see.

There is also a philosophical view according to which individuals are reducible to tropes, as maximal sets or 'bundles' of 'collocated' tropes. This view, though, will not play a role in this paper, as it does not bear on issues concerning natural

\footnotetext{
5 The term 'sparse property', which contrasts with the term 'abundant property', is that of David Lewis. The term 'natural property', as opposed to the term 'non-natural property', is that of David Armstrong.

${ }^{6}$ On an alternative view, universals are primitive classes of tropes, not defined in terms of resemblance (cf. Stout 1952). See Maurin (2002) for discussion.
} 
language semantics. For present purposes I will rather take individuals and tropes to constitute two distinct ontological categories. ${ }^{7}$

If properties are identified with functions from indices to sets of possible tropes, what is the meaning of an adjective? I will not identify the meaning of adjectives directly with such functions. Rather I take the function (or a later modification of it) to constitute the concept associated with adjectives (the comparative concept of the adjective). Adjectives in the positive and adjectives in the comparative (as well as other forms of adjectives) then have meanings that are in some way obtained from their comparative concept.

If an individual $d$ has a property expressed by a predicate $P$ of natural language in a world $w$ at a time $i$, then a function $f$ can apply to $d, P, w$, and $i$ and map them onto the trope that is the manifestation of the property expressed by $P$ in $d$ in $w$ at $i$. Thus, the denotation of John's happiness can be given as follows:

$$
[\text { John's happiness }]^{\mathrm{w}, \mathrm{i}}=\mathrm{f}(\mathrm{John}, \text { happy, w, i })
$$

Later I will also make use of properties in the second place of such functions.

As a general principle I take adjectives in a particular form to have a trope argument position just in case there are modifiers of the adjective in that form that act as predicates of tropes. Adjectives in the positive form will have an argument position for tropes as well as for individuals. In the next section, we will see that the range of modifiers that adjectives take makes up just the range of predicates of tropes. ${ }^{8}$

Two relations are central in the ontology of tropes: resemblance among tropes and the relation of a trope to its bearer. The identity and the existence of a trope depends on its bearer. A trope obviously inherits its location from its bearer: the redness of the box is located in time and in space wherever the box is located. Like the spatio-temporal location of the individual that is its bearer, the spatio-temporal

\footnotetext{
${ }^{7}$ Aristotle and Neo-Aristotelians such as Lowe (2006) are proponents of the view that individuals and tropes form two separate ontological categories; Williams (1953), Bacon (1995), Campbell (1990), and Simons (1994) are proponents of the view that individuals are reducible to tropes, as bundles of collocated tropes.

${ }^{8}$ Another important ontological role for which tropes have been considered is as truthmakers (Mulligan et al. 1984; Maurin 2002). Tropes in that role are what grounds the truth of sentences or propositions. Thus the truthmaker of John is happy is the trope that is the happiness of John. It is in virtue of that trope that the sentence is true. The truthmaking view of tropes takes tropes to be entities in the world and thus predicts groundedness: tropes as truthmakers must be entities truly in the world.

The view of tropes as truthmakers is less widely held and in fact the truthmaking idea-truth as a relation between entities and sentences or propositions-is itself rather controversial (see the contributions in Beebee and Dodd 2006).

If tropes play the role of truthmakers, this has implications for the semantics of adjectives. If tropes enter the semantic structure of sentences only via the truthmaking relation, then adverbial modifiers would be predicates of truthmakers, as in the analysis of (2a) in (2b), where $\vdash$ is the truthmaking relation (Moltmann 2007):
}

(2) a. Somehow John is happy.

b. $\exists \mathrm{t}$ ( $\operatorname{somehow}(\mathrm{t})$ and $\mathrm{t} \vdash$ John is happy)

I will not adopt the view that tropes play primarily the semantic role of truthmakers. In fact, the semantics of comparatives requires tropes to play a role as arguments of adjectives, which imposes an ordering among them. 
location of the trope appears accidental, rather than constitutive of the trope. If the box had been destroyed earlier than it was, then the redness of the box would not have lasted as long as it did. Moreover, if the box had been elsewhere than it was, then also the location of the redness of the box would have been a different one. However, a trope does not inherit its part structure from its bearer. In general, tropes appear to belong to the mass domain regardless of the part structure and unity of their bearer. For example, given Mary's beauty and Sue's beauty, the 'sum' of those two tropes is denoted by the mass term Sue's and Mary's beauty, not by the plural Sue's and Mary's beauties. Some tropes, like the redness of the box, do not seem to come with any part structure reflecting the part structure of the bearer; other tropes like the multi-coloredness of the statue obviously do involve a part structure, without that part structure necessarily displaying the part structure of the statue as such. Whether a trope does or does not display a part structure obviously depends on the kind of quality it displays, not on whether its bearer has a particular part structure as such. ${ }^{9}$

Any adjective nominalization may also refer to entities with variable trope manifestations, as in (12):

(12) a. The beauty of the landscape has changed.

b. The intensity of the sound has increased.

What these adjective nominalizations refer to are continuous entities that manifest themselves as possibly different tropes at different times. Still, all those tropes resemble each other. Thus all the beauty tropes of the landscape at different times resemble each other by being 'beauty'.

Besides tropes that are instances of one-place properties, there are tropes that are instances of relations. Thus, John's love for Mary is the instantiation of the loving relation in John and in Mary. Like nonrelational tropes, such relational tropes crucially enter relations of resemblance and depend on their bearers. However, we have only weak intuitions about the spatial location of relational tropes (they seem to be located not or not only where their bearers are located but possibly also on the path of things happening between them). ${ }^{10}$

Tropes may themselves act as the bearer of other tropes, of higher-order tropes. An example is the trope that is the intensity of John's happiness or the trope that is the exquisiteness of the beauty of the landscape.

Tropes obviously exhibit a close relation to events. In fact some philosophers do not hesitate to include events among the category of tropes or tropes among the category of events. The original interests in tropes and in events were quite

\footnotetext{
9 The mass status of tropes can be related to the fact, discussed by Levinson (1980) and Schnieder (2004) among others, that tropes sometimes lack a unique bearer (or so it seems). For example, a trope may have both an object and the matter constituting it as bearers. Thus the redness of the sweater is intuitively exactly the same trope as the redness of the wool of the sweater.

${ }^{10}$ For a discussion of the spatial-temporal location of relational tropes see Campbell (1990). Relational tropes raise other issues. For example, if individuals are viewed as bundles of collocated tropes, should relational tropes be included in those bundles (Bacon 1995) or not (Campbell 1990)? Campbell, in fact, maintains the (rather controversial) view that relational tropes are in fact reducible to non-relational tropes. But see Mertz (1996) for an extensive defence of relational tropes.
} 
different, though. The main interest in tropes in contemporary metaphysics has been centered around the reduction of properties and sometimes individuals to them. Events, by contrast, have received attention for other reasons, such as causation, adverbial modification, and time. Like tropes, events are grounded: events can be described and evaluated with respect to their internal structure (which goes 'below' the event description). Events, moreover, are concrete, acting as relata of causal relations and objects of perception, and by being spatio-temporally located. There is a fundamental ontological difference between events and tropes, though. Whereas tropes are instances of static properties, events are best viewed as instances of relations of transition in time from one trope to another, that is, as relational tropes of a certain sort (cf. Mertz 1996). This difference goes along with an interesting difference in the temporal nature of events: extendedness in time is constitutive of events, but not of tropes. This is because relations of temporal transition are constitutive of events, but temporal properties or relations are not constitutive of tropes. Moreover, we will see that adjectives provide a quantitative ordering among tropes, but not so for verbs and events. There are also semantic parallels: just as adverbial modifiers are naturally viewed as predicates of events, adjectival modifiers are naturally viewed as predicates of tropes, as we will see in the next section.

\subsection{First empirical evidence for tropes: the range of adjective modifiers}

The range of modifiers that are possible with adjectives presents a first, rather striking kind of evidence for tropes playing a central role in the semantics of adjectives. Whereas some adjectives allow for modifiers that could be viewed as predicates of degrees (very, much, highly, two meters, ten kilo), the full range of adjective modifiers can only be considered predicates of tropes, but not of degrees. At least five classes of such modifiers can be distinguished:

[1] modifiers making reference to the particular way the property is manifested:
a. exquisitely / strangely beautiful
b. intensely / uniformly / profoundly red

Clearly degrees cannot be exquisite, strange, intense, uniform, or profound. But tropes, the particular manifestation of properties in objects, naturally can.

[2] modifiers making reference to the perceivability of the property manifestation:

visibly / perceivably happy

Degrees as abstract entities are not perceivable, but tropes, as concrete entities, certainly are.

[3] modifiers making reference to the causal (including emotional) effect of the property manifestation: 

a. fatally weak
b. exhaustingly long

Degrees as abstract objects, on most philosophers' views, are not possible relata of causal relations, but tropes are (for philosophers that accept them).

[4] modifiers making reference to the role of the property manifestation as an object of action:

\section{(16) deliberately silent}

Tropes, just like events, naturally act as the target of actions, but not abstract objects of the sort of degrees.

[5] evaluative predicates which seem to concern the (unexpected) degree to which an entity has a property:

(17) a. John is remarkably tall.

b. The remark was shockingly inadequate.

c. The baby is surprisingly ugly.

Such adverbials are not straightforwardly accounted for on a degree-based analysis. Thus, Morzycki (2008), who adopts a degree-based account of adjectives, proposes an implicit exclamative as the object to which evaluative modifiers like remarkably apply ('it is remarkable how tall $\mathrm{x}$ is'). The trope-based analysis can analyse such modifiers in exactly the same way as other adjective modifiers, namely as predicates of tropes. Thus, (17a) is analysed as 'John's height is remarkable', (17b) as 'the inadequacy of the remark is shocking', and (17c) as 'the ugliness of the baby is surprising'.

There is thus a great range of adjective modifiers that are best viewed as predicates of tropes. Taking tropes to act as implicit arguments of predicates, this means that (18a) can be analysed as in (18b), which would be parallel to the Davidsonian account of adverbial modifiers as predicates of implicit event arguments of verbs:

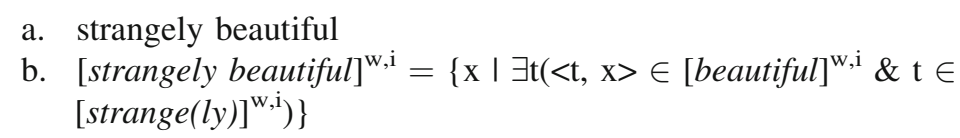

Not all adjective modifiers can be viewed as predicates of particular tropes, however. Adjective modifiers like completely, partially and very cannot be considered predicates of particular tropes, but should be considered predicates that apply to trope types and make reference to a scale of trope types. I will return to those later.

\subsection{Comparatives comparing tropes}

Let us now turn to the semantics of comparatives, which will shed further light on the ontology of tropes themselves. The point of departure of the trope-based 
analysis of comparatives is that comparatives such as (19a) are equivalent to (19b) or $(19 \mathrm{c}):^{11}$

(19) a. John is happier than Mary.

b. John's happiness exceeds Mary's happiness.

c. John's happiness is greater than Mary's happiness.

That is, (19a) is equivalent to a sentence that expresses a simple 'exceed'-relation between entities that the corresponding adjective nominalizations refer to. This relation is, it appears, a unified relation, a relation that could apply to nominalizations of any adjectives, for example also to (20a), as in (20b):

(20) a. Mary is sadder than John.

b. Mary's sadness exceeds / is greater than John's sadness.

Comparatives may also express a comparison between relational tropes, namely with gapping, as in $(21 \mathrm{a}, \mathrm{b})$ :

(21) a. Joe is more in love with Mary than Bill is with Jane.

b. John is more talented in mathematics than Sue is in music.

Thus, (21a) is intuitively equivalent to "the love of John for Mary exceeds the love of Bill for Jane', and (21b) to 'John's talent for mathematics exceeds Sue's talent for music'.

Comparatives may also compare higher-order tropes, as reflected in the paraphrase of (22a) in (22b):

(22) a. John's house is more distant from Mary's house than Bill's is from Sue's.

b. The distance from John's house to Mary's exceeds the distance from Bill's house to Sue's.

That is, (22a) involves two first-order nonrelational tropes and two second-order relational tropes.

One immediate advantage of the trope-based analysis of comparatives suggested by these paraphrases is that no abstract, rarely explicit entities such as degrees or sets of degrees are used. Rather all that is used are entities speakers make reference to anyway, namely tropes, which are also the referents of nominalizations of adjectives. As a consequence, the analysis does not face the conceptual problems of meaning-intention and indeterminacy.

11 (19a) is also equivalent to the sentence below:

(1) John exceeds Mary in happiness.

Obviously here the exceed-relation does not apply to its two arguments as such, but rather relative to a respect ('in happiness'). Apparently, across languages, this kind of construction is an alternative to comparatives as in (19a) as well as constructions like (19b) (Sigrid Beck, Pers. Comm.). 
The paraphrases given so far cannot quite give the semantics of comparatives, though. One problem is that nominalizations sometimes have implications that simple comparatives do not have. The paraphrase in (19b) implies that for (19a) to be true both John and Mary in fact must be involved in a happiness trope, and thus must both, in some way, be happy, for one to be happier than the other. In fact, even when a person is in fact unhappy, there should be a happiness trope for that person. In the majority of cases, in fact, the comparative does imply that the two entities have the properties to a positive extent, for example with is whiter than, is more artificial than or is more flexible than. But this is not the case for other adjectives, such as clean, long, tall, and small.

There are further difficulties in taking the paraphrase to unveil the meaning of the comparative. According to the paraphrase, the 'exceed'-relation can be read off the entities that the nominalizations refer to: given two tropes, John's strength and Bill's strength, we know what needs to be the case for one to exceed the other. The exceed-relation between John's strength and Bill's strength, in other words, is an internal relation (a relation that obtains in virtue of the entities themselves), rather than an external relation (a relation that obtains in virtue of the circumstances in which the entities find themselves). This raises two potential problems for the standard view of tropes.

The first potential problem is what one may call the single-respect problem. This is the problem of why there should be only a single 'exceed'-relation holding among two tropes of the same type. If tropes are located and extended in space and time, then why should (19a) not have a reading on which John's happiness lasted longer (though was less intense) than Mary's or on which John is bigger than Mary while being happy. Such readings are entirely excluded. Only the qualitative respect and not any spatio-temporal features are available for a quantitative comparison of tropes. There is an explanation available for that, though, given earlier remarks about the spatio-temporal location of tropes: the spatio-temporal location and spatial and temporal extendedness of tropes are only accidental, not constitutive features of tropes, and it is reasonable to assume that the 'exceed'-relation takes into account only constitutive, not accidental features of its arguments. ${ }^{12}$

There is a more serious problem for the standard conception of tropes, and that is what I call the problem of direction. This is the problem of how we can tell, given two tropes of the same type such as Sue's strength and Mary's strength, which one is greater than the other. At first, the answer to the question seems entirely straightforward: we just need to test Sue's strength and Mary's strength, that is, examine those two tropes, to see which one is 'greater than' the other. But a problem arises when referring to tropes with nominalizations of the negative element of a pair of two antonymous adjectives, for example Sue's weakness and Mary's weakness. The

\footnotetext{
12 Alternatively, to avoid a distinction between accidental and constitutive features of tropes, one might argue that tropes have spatio-temporal properties only derivatively, those being inherited from the spatiotemporal location of the individual that is the bearer of the trope. The exceed-relation would then take into account only basic, not derivative features of entities.
} 
tropes that are Sue's weakness and Mary's weakness will clearly also be involved in the semantics of the comparative weaker, as in the paraphrase of (23a) in (23b):

a. Mary is weaker than Sue.

b. Mary's weakness exceeds Sue's weakness.

When we refer to two tropes as 'Mary's weakness' and 'Sue's weakness', it is also intuitively clear what needs to be the case for one to exceed the other. But now suppose that in a given context Mary's strength (supposing that it is 'negligible') is identical to Mary's weakness. Such a possible identity seems needed in view of valid inferences such as (24):

$\frac{\text { Sue is stronger than Mary. }}{\text { Mary is weaker than Sue. }}$

Given the present account, the premise of (24) implies that there is such a thing as Mary's strength and the conclusion that there is such a thing as Mary's weakness. Polar adjectives like weak and strong clearly are applied to an individual on the same physical basis, the relevant physical condition, and thus on the basis of one and the same trope. This means that there will be one and the same trope $t$ that is the referent both of Mary's weakness and of Mary's strength. If we try to compare $t$ to the trope $t$ ' that we could refer to either as 'Sue's weakness' or as 'Sue's strength', we will have the 'greater than'-relation applying in two different directions: $t$ is greater than $t^{\prime}$ (as a weakness), and $t^{\prime}$ is greater than $t$ (as a strength). This of course cannot be; in other words, the following inference is invalid:

(25) Mary's weakness exceeds Sue's weakness.

Sue's strength exceeds Mary's strength.

Sue's strength $=$ Sue's weakness.

Mary's weakness = Mary's strength.

Sue's weakness exceeds Mary's weakness.

Clearly the extent of the weakness of a person increases the weaker the person is, something which is also reflected in the use of modifiers like great and negligible ('great weakness' is that of a weaker person than a person that has 'little weakness' or 'negligible weakness').

The same reversal among the ordering of tropes can be observed with the nominalizations of any pair of polar adjectives (darkness - lightness, equality inequality, experience - inexperience).

The problem of direction arises not only with the 'greater than'-relation, but also when applying quantitative adjectives like great or negligible. We know (roughly) what needs to be the case so that Sue's strength is great and Mary's strength is negligible, and if that is in fact the case (speaking of the same type of physical strength), then Sue's strength exceeds Mary's strength, that is, Sue is stronger than Mary.

The problem of direction is a serious problem for the standard view of tropes applied to adjective nominalizations. Where does the ordering among tropes come 
from, if it cannot have its source in the nature of the tropes, as standardly conceived? The answer can only be that the ordering is imposed by, and thus part of, the concept that is expressed by the adjective in question. As Engel (1989) has emphasized, extensions and intensions do not suffice for making up the properties that adjectives express, rather it is the 'degree structure' that is constitutive of those properties as well. For example, the properties 'being between $m$ and $n$ meters tall' and 'being tall', apart from the one property being vague and the other not, may, in a given context, have the same intension and extension, but whereas the former will involve no ordering (according to degrees), the latter will. Being able to learn and use the concept expressed by a gradable adjective means not only knowing under what circumstances the concept is true of an object, but also knowing under what circumstances one entity, as an instance of the concept, exceeds another instance of the concept. ${ }^{13}$

Thus gradable adjectives will not just describe a set of tropes or rather a function from indices to sets of tropes, but rather an ordering among tropes or rather a function from indices to ordered sets of tropes. This ordering is what predicates like greater than or exceed with nominalizations make reference to, but it is also expressed by the comparative itself. I will call the function from indices to ordered sets of tropes the comparative concept expressed by the adjectives. The comparative concept is obviously closely related to (though, as we will see, not identical with) the meaning of the adjective in the comparative form. But it also underlies the meaning of adjectives in the positive form and the meaning of nominalizations.

There are reasons to have the ordering involved in the comparative concept not only relate tropes in the same world at the same time to each other, but also tropes across different worlds and across different times. This is quite obviously needed for examples like those below:

(26) a. I thought your yacht was longer than it is.

b. If your yacht was longer than it is, I would be envious.

c. The cat is bigger now than it was a year ago.

The trope-based analysis can account for such sentences as long as possible tropes are admitted and tropes from different worlds and times are ordered with respect to each other.

The comparative concept should also account for the semantics of equatives, as in (27):

\footnotetext{
(1) a. Hans ist vergleichbar talentiert wie Maria. 'John is comparably talented as Mary.'

b. Mary ist aehnlich attractive wie Anna. 'Mary is similarly attractive as Ann is.'

c. John ist anders begabt als Maria es ist. 'John is differently talented than Mary is.'
}

13 One might ask whether there are comparative constructions that compare tropes in qualitative respects. In fact, there are constructions of that sort in some languages. For example, German equatives and comparatives allow for modifiers like comparably, similarly, or differently:

Such comparative constructions do not just compare the extent to which the property in question is manifested, but rather they express relations of similarity and qualitative difference among tropes. 
If the comparative concept involves the proper exceed-relation, there will be difficulties accounting for the equative: (27) means neither that John's strength properly exceeds Mary's and vice versa, nor that John's strength does not exceed Mary's and Mary's does not exceed John's (in which case John's and Mary's strengths may just be incompatible). Rather it means that John's strength exceeds or is equal to Mary's strength and Mary's exceeds or is equal to John's. Thus what is needed is a relation of 'exceeding or being equal to'. This relation is transitive, reflexive, but not antisymmetric (two tropes that are equal are thereby not identical). The comparative concept of an adjective can thus be characterized as follows, where $W$ is the set of worlds and $I$ the set of times:

(28) The comparative concept $\mathrm{f}(\mathrm{A})$ of an adjective $\mathrm{A}$ is a function from world-time pairs to sets of tropes such that $\left(\cup\{\mathrm{T} \mid \exists \mathrm{w} \in \mathrm{W} \exists \mathrm{i} \in \mathrm{If}(\mathrm{A})(\mathrm{w}, \mathrm{i})=\mathrm{T}\}, \leq_{\mathrm{A}}\right)$ is a transitive and reflexive ordering.

In the case of comparatives like stronger and weaker, we have two comparative relations that apply in the inverse order to the same tropes.

Making use of the comparative concept, the semantics of phrasal comparatives can now be given as in (29a), with the denotation of the comparative form as in (29b): ${ }^{14}$

\footnotetext{
14 The analysis of comparatives in (29a) has another desirable, formal feature. It predicts that there will be no scope-interaction effects of a possible degree quantifier with negation and other quantifiers in the same sentence, just as in fact on Kennedy's (1999) version of the degree-based account, which takes gradable adjectives to express measure functions (though see Heim (2006) for critical discussion). Consider (1a), which is analysed as in (1b), given the lexical analysis of happier in (29b):
}

(1) a. John is not happier than Mary

b. $\neg \lambda \mathrm{x} y\left[\exists \mathrm{t} \exists \mathrm{t}^{\prime}\left(\mathrm{t} \in \mathrm{f}(\right.\right.$ happy $)(\mathrm{w}, \mathrm{i}) \& \mathrm{~B}(\mathrm{x}, \mathrm{t}) \& \mathrm{t}^{\prime} \in \mathrm{f}($ happy $\left.\left.)(\mathrm{w}, \mathrm{i}) \& \mathrm{~B}\left(\mathrm{y}, \mathrm{t}^{\prime}\right) \& \mathrm{t}>_{\text {happy }} \mathrm{t}^{\prime}\right)\right]$ (John, Mary)

Clearly this analysis allows negation to take only wide scope over the two trope quantifiers and no degree quantifier is around anyway.

For the same reason the quantifier expressed by few men in (2a) can take only wide scope over any trope quantifier:

(2a) few men are happier than Mary

Thus in particular (1a) cannot have a reading that would correspond to the analysis in (1c), and (2a) cannot have a reading that would correspond to the analysis in $(2 \mathrm{c})$ :

(1) c. $\max d[\neg$ happy(John, d)] $\geq \max d[$ happy(Mary, d)]

(2) b. $\max d[\mathrm{FEW} x[\operatorname{men}(\mathrm{x})][\operatorname{happy}(\mathrm{x}, \mathrm{d})]] \geq \max d[\operatorname{happy}($ Mary, d)]

That is, (1a) cannot mean 'the maximal degree to which John fails to be happy exceeds the maximal degree of Mary's happiness, and (2a) cannot mean 'the maximal degree d such that few men are happy to degree d exceeds the (maximal) degree to which Mary is happy'. Instead (1a) has only the reading 'the (maximal) degree of John's happiness does not exceed the (maximal) degree of Mary's happiness', and (2a) has only the reading 'for few men $x$, the maximal degree to which $x$ is happy exceeds the maximal degree to which Mary is happy'. These two readings are the ones an analysis as in (1b) predicts. 

a. [John is happier than Mary] ${ }^{\mathrm{w}, \mathrm{i}}=1$ iff $\exists \mathrm{t} \in \mathrm{D}(\mathrm{w}, \mathrm{i}) \exists \mathrm{t}^{\prime} \in \mathrm{D}(\mathrm{w}, \mathrm{i})$ $\left(\mathrm{t} \in \mathrm{f}(\right.$ happy $)(\mathrm{w}, \mathrm{i}) \& \mathrm{t}^{\prime} \in \mathrm{f}\left(\right.$ happy) $(\mathrm{w}, \mathrm{i}) \& \mathrm{t} \leq_{\text {happy }} \mathrm{t}^{\prime} \& \neg \mathrm{t}^{\prime} \leq_{\text {happy }} \mathrm{t}$ \& $\mathrm{B}($ John, $\mathrm{t}) \& \mathrm{~B}\left(\right.$ Mary, $\left.\left.\mathrm{t}^{\prime}\right)\right)$
b. $\quad[\text { happier }]^{\mathrm{w}, \mathrm{i}}=\left\{<\mathrm{x}, \mathrm{y}>\mid \exists \mathrm{t} \exists \mathrm{t}^{\prime}\left(\mathrm{t} \in \mathrm{f}(\right.\right.$ happy $)(\mathrm{w}, \mathrm{i}) \& \mathrm{t}^{\prime} \in \mathrm{f}($ happy $)(\mathrm{w}, \mathrm{i})$ $\left.\left.\& \mathrm{t} \leq_{\text {happy }} \mathrm{y} \& \neg \mathrm{t}^{\prime} \leq_{\text {happy }} \mathrm{t} \& \mathrm{~B}(\mathrm{x}, \mathrm{t}) \& \mathrm{~B}\left(\mathrm{y}, \mathrm{t}^{\prime}\right)\right)\right\}$

Here $D(w, i)$ is the domain of the world $w$ at time $i$, and $B$ is the relation that holds between an individual and a trope of which it is a bearer.

The adjectival concept moreover serves as the basis of the semantics of the equative:

$$
\begin{aligned}
& {[\text { as happy as }]^{\mathrm{w}, \mathrm{i}}=\left\{<\mathrm{x}, \mathrm{y}>\mid \exists \mathrm{t} \exists \mathrm{t}^{\prime}\left(\mathrm{t} \in \mathrm{f}(\text { happy })(\mathrm{w}, \mathrm{i}) \& \mathrm{t}^{\prime} \in \mathrm{f}(\text { happy })(\mathrm{w}, \mathrm{i})\right.\right.} \\
& \left.\left.\& \mathrm{~B}(\mathrm{x}, \mathrm{t}) \& \mathrm{~B}\left(\mathrm{y}, \mathrm{t}^{\prime}\right) \& \mathrm{x} \leq_{\text {happy }} \mathrm{y} \& \mathrm{y} \leq_{\text {happy }} \mathrm{x}\right)\right\}
\end{aligned}
$$

The adjectival concept will also serve as the basis for the semantics of the positive, as we will see in the next section.

The role of the comparative concept is apparent also when comparing adjective nominalizations with other trope-denoting nouns, such as form. Whereas (31a) is acceptable, with an adjective nominalization, (31b) is not, with a trope-denoting underived noun:

\footnotetext{
a. The straightness of the first rope exceeds the straightness of the second rope.

b. *The form of the first rope exceeds the form of the second rope.
}

Even though the straightness of the rope and the form of the rope should make reference to the same configurational trope, the 'greater than'-relation is applicable only to the former, not to the latter. The reason is that straightness is derived from an adjective which describes a comparative relation among tropes.

The ordering among the tropes is imposed by the adjectival concept itself; it is not a relation to be read off the tropes as understood on the standard view (that is, as the entity that makes it true that a predicate holds of an object). But it should be a relation that can be read off the kind of entities that nominalizations such as Mary's weakness or Mary's strength refer to. If we call tropes as conceived on the standard view standard tropes, then the referents of adjective nominalizations should be entities that are in some sense more complex than standard tropes, entities for which the relevant relation to other tropes is also constitutive. Let us call such tropes order-constituted tropes. Order-constituted tropes are complex tropes of some sort, consisting of a simple trope $t$ (such as a physical condition) as well as relational tropes, namely instances of the 'greater than'-relation in $t$ and any other possible trope of the same type. If $c$ is the relevant operation of composition, then the trope that is Mary's strength will look as follows:

$$
\begin{aligned}
& {[\text { Mary's strength }]^{\mathrm{w}, \mathrm{i}}=\mathrm{c}\left(\{ \mathrm { t } | < \mathrm { t } , \text { Mary } > \in [ \text { strong } ] ^ { \mathrm { w } , \mathrm { i } } \} \cup \left\{\mathrm{r} \mid \exists \mathrm{t}^{\prime}\left(\mathrm{t}^{\prime} \in \mathrm{f}(\text { strong })\right.\right.\right.} \\
& \left.\left.\left.(\mathrm{w}, \mathrm{i}) \&\left(\mathrm{r}=\mathrm{f}\left(\mathrm{t}, \mathrm{t}^{\prime}, \leq, \mathrm{w}, \mathrm{i}\right) \vee \mathrm{r}=\mathrm{f}\left(\mathrm{t}^{\prime}, \mathrm{t}, \leq, \mathrm{w}, \mathrm{i}\right)\right)\right)\right\}\right)
\end{aligned}
$$


I will leave it open whether $c$ is mere mereological composition or rather leads to a more structured complex with $t$ constituting a sort of nucleus and the relational tropes a shell. ${ }^{15}$ What is most important is that any general 'greater than'-relation that applies to order-constituted tropes must take into account only constitutive features of that complex and thus must apply in conformity with the relational tropes that are part of the order-constituted trope. ${ }^{16}$

Events do not exhibit the same evidence for a lexically imposed ordering. That is, there is no reason to assume that eventive verbs denote ordered sets of events. The verb exceed has several readings with event nominalizations and not just the single 'degree' reading that it has with adjective nominalizations:

a. John's happiness exceeded John's sadness.

b. John's laughter exceeded John's crying.

Whereas (33a) can only mean that the 'degree' to which John is happy exceeded the degree to which he is sad, the exceed-relation expressed in (33b) can compare John's laughter and John's crying in various respects, e.g. in intensity, length of time, or frequency of occurrence.

There are also much weaker restrictions of commensurability on adverbial comparatives. Events of different types can be compared much more easily than tropes: ${ }^{17}$
a. John has laughed more than he has cried.
b. \# John is happier than he is sad.

\begin{abstract}
15 The same kind of composition might be responsible for differences among events such as the pulling of the trigger, the shooting, the killing, and the triggering of a revolution, arguably different events that happen at the same spatio-temporal location. The relation among such events is what Goldman (1971) calls 'level-generation'. What distinguishes the pulling of the trigger and the shooting, for example, is that the latter involves a relation to another person.

16 An alternative account might be to make use of the notion of a qua object in the sense of Fine (1982) or rather of a 'qua-trope'. A qua object is formed from an individual (the base) and a gloss, a property. A qua object $d$ qua $P$ exists at a time $t$ in a world $w$ just in case $d$ has $P$ at $t$ in $w$, and two qua objects are identical just in case they have the same base and the same gloss (Fine 1982). The gloss for the kind of qua trope that is needed is the property of being ordered with respect to all the other tropes of the relevant class of possible tropes. Obviously Mary's weakness will then be a distinct entity from Mary's strength. A physical condition $t$, reduced to its role of instantiating the property of weakness (which as such includes an ordering among tropes) can 'exceed' another condition $t$ ' of the same sort only in the sense of $t$ 'being weaker than' $t^{\prime}$, that is, being ordered by the relation given by the gloss of the qua trope. The same physical condition $t$, qua being an instance of strength, by contrast, can exceed another condition of the same sort only by standing in the 'stronger than'-relation to it.

Fine's notion of a qua object was also meant to apply to events, to account for the difference among events such as a pulling of a trigger and a shooting, mentioned in FN 15.

17 The difference between adjectives and verbs with respect to qualitative equatives is particularly striking in German, where the same equative construction can be used both for verbs and for adjectives. When applied to verbs, the equative can express both qualitative and quantitative equivalence among events, whereas when applied to adjectives, the equative can only express quantitative equivalence among tropes:
\end{abstract}

(1) a. Hans hat ebenso gelacht wie Maria.

'John has laughed in the same way / to the same extent as Mary.'

b. Hans ist ebenso talentiert wie Maria.

'John is talented to the same extent as Mary.' 
This is because events are not compared with respect to the order imposed by an adjective, but rather according to independent criteria. That is because whereas adjectives describe sets of ordered tropes, eventive verbs describe un-ordered sets of events, that is, transition tropes.

Why do verbs, event concepts, not impose an ordering on events? This, it seems, has to do with the ontological nature of events. Tropes are instantiations of gradable properties, properties imposing an ordering on tropes. Events, by contrast, are second-order relational tropes in which two or more first-order tropes instantiate a relation of temporal transition. It is then natural that event concepts will not impose an ordering: there is no point in imposing an ordering among transition tropes. Events can be compared in extent only in other respects, for example by comparing the tropes involved in them or their subevents, or by comparing their temporal duration.

\subsection{Trope types}

It is not only particular tropes that play a role in the semantics of adjectives. There are various semantic phenomena that involve types of tropes. We have already seen that possible tropes are needed in intensional contexts. Types of tropes can be conceived as sets of possible tropes. They are involved in at least two kinds of contexts: [1] noninstantiated standards of relative adjectives in the positive form and [2] modifiers such as completely, partially, perfectly, half, and almost. With appropriate notions of a trope type and a trope type scale, we can give a trope-based reformulation of semantic generalizations about adjective modifiers and scale structures of different kinds of adjectives which have come to play an important role in the degree-based literature. Moreover, there are tropespecific generalizations which give the trope-based analysis an advantage over degree-based analyses. Let us turn to the relevant definitions of trope type and trope-type scale.

I adopt the standard analysis of the positive form of relative adjectives on which the positive expresses a relation to a contextually given standard. The semantics of the positive is thus based on the comparative concept of the adjective. Given the trope-based analysis, tall will express the property that holds of an individual $x$ just in case there is a height trope of $x$ that exceeds the contextually given standard. It is quite obvious that the contextual standard of a relative adjective like tall may have no actual instances. It should be construed as a type of trope, consisting of possible tropes, rather than as an actual trope. The tropes making up the standard, moreover, need not form a single equivalence class of possible tropes with respect to the relation $\leq$, but rather may consist in an 'interval' (with vague borders) made up from such equivalence classes (Schwarzschild and Wilkinson 2002). For an adjectival comparative relation $\leq_{\mathrm{A}}$, we can then define a trope type and a trope type interval as follows: 
Definition of Trope Types

a. For an adjective $A$, the set of trope types of $\mathrm{f}(\mathrm{A})$, typ $(\mathrm{f}(\mathrm{A}))$, is the set $\left\{\mathrm{T}^{\prime} \mid \forall \mathrm{t}, \mathrm{t}^{\prime} \in \mathrm{T}^{\prime}\left(\mathrm{t} \leq_{\mathrm{A}} \mathrm{t}^{\prime} \& \mathrm{t}^{\prime} \leq_{\mathrm{A}} \mathrm{t}\right)\right\}$

b. For an adjective $A$, an interval of the set of trope types $T$ is a subset $\mathrm{T}^{\prime}$ of $\cup \mathrm{T}$ such that for any $\mathrm{t}, \mathrm{t}^{\prime} \in \mathrm{T}^{\prime}$, if for some $\mathrm{t}^{\prime \prime}, \mathrm{t} \leq_{\mathrm{A}} \mathrm{t}^{\prime \prime}$ and $\mathrm{t}^{\prime \prime} \leq_{\mathrm{A}} \mathrm{t}^{\prime}$, then $\mathrm{t}^{\prime \prime} \in \mathrm{T}^{\prime}$.

If we take the standard (a trope type interval) to be obtained by applying a function $s$ to the context $c$ and the comparative concept, then a relative adjective like tall in the positive form will express the property below, where $s$ is a function mapping a context and the comparative concept of an adjective to the standard of the adjective in that context:

$$
\begin{aligned}
& \mathrm{x} \in\left[\text { tall }_{\text {pos }}\right]^{\mathrm{c}, \mathrm{w}, \mathrm{i}}=1 \text { iff for some trope } \mathrm{t}, \mathrm{B}(\mathrm{x}, \mathrm{t}) \text { and }<\mathrm{t}, s(\mathrm{c}, \mathrm{f}(\text { tall }))> \\
& \in \mathrm{f}(\text { tall })(\mathrm{w}, \mathrm{i})
\end{aligned}
$$

Here the comparative relations need to be extended to trope types, that is, sets of tropes: a comparative relation = holds between a trope $t$ and a set of tropes $T$ just in case it holds between $t$ and any trope $t^{\prime}$ in $T$. Moreover, comparative relations should hold between two trope types just in case they hold between any two tropes belonging to the trope types:

a. For a trope $\mathrm{t}$ and a trope type $\mathrm{T}, \mathrm{t} \leq \mathrm{T}(\mathrm{T} \leq \mathrm{t})$ iff for all $\mathrm{t}^{\prime} \in \mathrm{T}, \mathrm{t} \leq \mathrm{t}^{\prime}$ $\left(\mathrm{t}^{\prime} \leq \mathrm{t}\right)$.

b. For trope types $T$ and $T^{\prime}, T \leq T^{\prime}$ iff for all $t \in T, t^{\prime} \in T^{\prime}, t \leq t^{\prime}$.

Let us next turn to modifiers making reference to trope types. If an entity $x$ is completely dirty or partially dark, then 'completely' and 'partially' locate a darkness trope of $x$ at a certain area of the scale of trope types of $x$. These trope types may be ordered in two ways: by the 'degree' of darkness or by the extent or amount of the parts of $x$ that bear a darkness trope. Completely can relate to either trope type scale (that is, it has a reading involving the maximal degree and a reading involving a maximal number of parts); partially can relate to only the former. Whereas standards of relative adjectives are object-independent, the scale of trope types that completely and partially relate to are object-dependent: if $x$ is completely dark, this means that there is a trope of complete darkness of $x$ that is one among the maximal possible darkness tropes of $x$.

Let us first define the notions of an object-dependent degree-related trope type and of an object-dependent degree-related trope type scale:

a. Definition of Object-Dependent Degree-Related Trope Types

For an adjective $\mathrm{A}$ and an object $\mathrm{d}$, the set of degree-related trope types of $\mathrm{f}(\mathrm{A})$ for $\mathrm{d}, \mathrm{D}-\operatorname{typ}(\mathrm{d}, \mathrm{f}(\mathrm{A}))=\left\{\mathrm{T}^{\prime} \mid \forall \mathrm{t}, \mathrm{t}^{\prime} \in \mathrm{T}^{\prime}\left(\mathrm{B}(\mathrm{d}, \mathrm{t}) \& \mathrm{~B}\left(\mathrm{~d}, \mathrm{t}^{\prime}\right) \rightarrow\right.\right.$ $\left.\left.\mathrm{t} \leq_{\mathrm{A}} \mathrm{t}^{\prime} \& \mathrm{t}^{\prime} \leq_{\mathrm{A}} \mathrm{t}\right)\right\}$

b. Definition of a Object-dependent Degree-Related Trope Type Scale (D-Scale)

D-scale $(d, A)=\left\{<T, T^{\prime}>\mid T \in D\right.$-type $(d, f(A)) \& T^{\prime} \in D$-type $(d, f(A))$ $\left.\& \mathrm{~T} \leq_{\mathrm{A}} \mathrm{T}^{\prime} \& \forall \mathrm{t} \forall \mathrm{t}^{\prime}\left(\mathrm{t} \in \mathrm{T} \& \mathrm{t}^{\prime} \in \mathrm{T}^{\prime} \rightarrow \neg \mathrm{t}^{\prime} \leq_{\mathrm{A}} \mathrm{t}\right)\right\}$ 
Object-dependent part-related notions of a trope-type and a trope-type-scale are given below, where < is the part of-relation:

a. Definition of Object-Dependent Part-Related Trope Types

For an adjective $A$ and an object $d$, the set of part-related trope-types of $\mathrm{f}(\mathrm{A})$ for d, P-typ $(\mathrm{d}, \mathrm{f}(\mathrm{A}))=\left\{\mathrm{T}^{\prime} \mid \forall \mathrm{t}, \mathrm{t}^{\prime} \in \mathrm{T}^{\prime} \exists \mathrm{w} \in \mathrm{W} \exists \mathrm{i} \in \mathrm{I}\left(\mathrm{t}, \mathrm{t}^{\prime}\right.\right.$ $\in \mathrm{f}(\mathrm{A})(\mathrm{w}, \mathrm{i}) \& \forall \mathrm{d}^{\prime}, \mathrm{d}^{\prime \prime}\left(\mathrm{B}\left(\mathrm{d}^{\prime}, \mathrm{t}\right) \& \mathrm{~B}\left(\mathrm{~d}^{\prime \prime}, \mathrm{t}^{\prime}\right) \rightarrow \operatorname{ext}\left(\mathrm{d}^{\prime}\right) \leq \operatorname{ext}\left(\mathrm{d}^{\prime \prime}\right) \&\right.$ $\left.\left.\left.\operatorname{ext}\left(\mathrm{d}^{\prime \prime}\right) \leq \operatorname{ext}\left(\mathrm{d}^{\prime}\right)\right)\right)\right\}$

b. Definition of an Object-Dependent Part-Related Trope-Type Scale (P-Scale)

P-scale $(d, A)=\left\{<T, T^{\prime}>\mid T \in P-t y p(d, f(A)) \& T^{\prime} \in P\right.$-typ $(d, f(A)) \&$ $\forall \mathrm{t} \in \mathrm{T} \forall \mathrm{t}^{\prime} \in \mathrm{T}^{\prime} \forall \mathrm{d}^{\prime}, \mathrm{d}^{\prime \prime}\left(\mathrm{B}\left(\mathrm{d}^{\prime}, \mathrm{t}\right) \& \mathrm{~B}\left(\mathrm{~d}^{\prime \prime}, \mathrm{t}^{\prime}\right) \rightarrow \operatorname{ext}\left(\mathrm{d}^{\prime}\right) \leq \operatorname{ext}\left(\mathrm{d}^{\prime \prime}\right) \&\right.$ $\left.\left.\left.\neg \operatorname{ext}\left(\mathrm{d}^{\prime \prime}\right) \leq \operatorname{ext}\left(\mathrm{d}^{\prime}\right)\right)\right)\right\}$

Here ext is a function mapping an entity (such as a collection of parts) to its extent, an entity which can be viewed as a trope itself (Sect. 6).

Both a D-scale and a P-scale have a maximum as well as a minimum, as defined below:

(40) a. A minimum of a trope type scale $(\mathbf{T}, \leq)(\max (\mathbf{T}, \geq))$ is the trope type $\mathrm{T} \in \mathbf{T}$ such that for any trope type $\mathrm{T}^{\prime} \in \mathbf{T}, \mathrm{T} \leq \mathrm{T}^{\prime}$.

b. A maximum of a trope type scale $(\mathbf{T}, \leq)$ is the trope type $\mathbf{T} \in \mathbf{T}$ such that for any trope type $\mathrm{T}^{\prime} \in \mathbf{T}, \mathrm{T} \leq \mathrm{T}^{\prime}$.

Which scale a modifier makes reference to obviously depends both on the adjectival concept and the context, with some adjectives imposing the conditions that they may involve only one of the two types of scales. The meaning of completely may choose either trope type scale, and thus the context will help determine the trope type scale. As part of the meaning of completely, a function scale will map an object-dependent trope type and a context to a trope-type scale: ${ }^{18}$

$$
\begin{aligned}
& {[\text { completely } \mathrm{A}]^{\mathrm{c}, \mathrm{w}, \mathrm{i}}=\{\mathrm{xl} \exists \mathrm{t}(\mathrm{B}(\mathrm{x}, \mathrm{t}) \& \mathrm{t} \in \mathrm{f}(\mathrm{A})(\mathrm{w}, \mathrm{i}) \& \mathrm{t}=} \\
& \max (\operatorname{scale}(\mathrm{x}, \mathrm{f}(\mathrm{A})), \mathrm{c}))\}
\end{aligned}
$$

Absolute adjectives have a scale with a minimum or maximum, whereas relative adjectives have an open scale, a scale that lacks a minimum or maximum element. Adjectives like awake, visible, bent, and open specify a scale with a minimum; adjectives like asleep, invisible, full, flat, and straight a scale with a maximum.

There is a range of modifiers that are sensitive to scales having a minimum or maximum. Thus, the modifiers half and mostly apply only to adjectives with closed scales (with minimum or maximum element) (half open / half closed), but not to adjectives with open scales (* half long, * half short).

\footnotetext{
18 Moltmann (1997) gives a somewhat different analysis of the various readings of completely, namely in terms of different part structures of a type of state or event. Completely is taken to express a relation between a state or event $e$ and a type of state or event $E$ that holds in case every part of $E$ is instantiated by a part of $e$. It is hard to see what the parts of $E$ should be, though, on the degree-related reading.
} 
The notion of a standard is not only important for relative adjectives. Kennedy (2007) has argued that what distinguishes scales for absolute and for relative adjectives is not just the presence of a maximum or minimum, but also the way the standard for the positive is fixed. For relative adjectives, the standard is fixed by the context, whereas for absolute adjectives, the standard is an interval that includes the maximum (or minimum). Construing a standard as a trope-type interval that depends both on the context and the adjective concept allows for a straightforward trope-based reformulation of this generalization.

There are trope-type-related modifiers that provide particular evidence for tropes, as opposed to degrees. For example, perfectly is a modifier that makes reference to trope types and in fact also states that a trope belongs to a maximal trope type. But perfectly differs in meaning from completely. Perfectly does not require that a trope belongs to a maximal trope type. It also requires that the trope belong to a 'perfect' trope type. However such a gestalt-related meaning is to be made precise, it is clear that perfectly makes reference to trope types rather than degrees.

Another important distinction extensively discussed in the recent literature is that between total and partial adjectives (Yoon 1996; Rothstein and Winter 2004). There are many pairs of antonymous adjectives consisting of a partial and a total adjective, for example open/closed, dirty/clean, pure/impure, complete/incomplete. The distinction between total and partial adjectives is based on a single more fundamental condition, which I will call the base condition. Roughly, for a partial adjective to hold of an object, the object needs to partially fulfil the base condition; for a total adjective to hold of an object, the object needs to be free of the base condition. For example the base condition for dirty/clean is roughly 'being covered with dirt'. For $x$ to be dirty, $x$ needs to be covered with dirt somewhere, whereas for $x$ to be clean, $x$ needs to be free of dirt everywhere. ${ }^{19}$

One respect in which the distinction between partial and total adjectives manifests itself is with respect to plurals: partial adjectives imply only existential quantification, whereas total adjectives imply universal quantification over the members of the plurality (Yoon 1996):
a. The As are dirty. $\rightarrow$ Some of the As are dirty.
b. The As are clean. $\rightarrow$ All of the As are clean.

But more importantly, partial and total adjectives behave differently in the following two respects:

[1] Inference to the Positive: Partial and total adjectives behave differently as to whether they allow the inference to the positive. If $x$ is dirtier than $y$, then both $x$ and $y$ are dirty. But if $x$ is cleaner than $y$, then neither $x$ nor $y$ need to be clean. That is,

\footnotetext{
19 There is another kind of total/partial adjective pair, exemplified by dead/alive. For alive to be true of an entity, the entity (as such) needs to instantiate the condition to some extent, whereas for dead to be true of an entity, the entity should not instantiate the condition at all. Thus, there are in fact two kinds of partial/total adjective pairs: for one kind, some part of the entity needs to instantiate the property in question; for the other kind, the entity needs to instantiate the property to some extent.

Generally, the degree-based account characterizes the two cases by a single condition: for a partial adjective to be true of an entity, the entity just needs to have some degree of the condition in question, whereas for a total adjective to be true of an entity, the entity needs to have no degree of the condition.
} 
the comparative of partial adjectives validates Inference to the Positive, whereas the comparative of total adjectives does not.

[2] The acceptability of modifiers: There are a number of modifiers that distinguish between partial and universal adjectives. First, almost is possible with total adjectives only (almost clean, ?? almost dirty, almost dead, ?? almost alive). By contrast, slightly is possible with partial adjectives only (slightly dirty, ?? slightly clean).

The behaviour of total and partial adjectives at first seems to present a problem for the trope-based analysis. If $x$ is cleaner than $\mathrm{y}$ is analysed as 'the cleanliness of $x$ exceeds the cleanliness of $y^{\prime}$, then both $x$ and $y$ should be clean. That is, the tropebased account predicts, it seems, that Inference to the Positive is always possible.

Moreover, it is not obvious how the trope-based analysis accounts for the difference in behaviour with modifiers. Almost and slightly are not sensitive to minimum or maximum elements of a scale, and no other distinction among trope type scales is available as yet.

The trope-based analysis can account for both problems, though, by taking total and partial adjectives to describe tropes that are instances of quantificational properties, properties that quantify over tropes. Of course, there will be nothing quantificational about the tropes themselves: tropes are real entities that make the quantificational condition true, but they are not themselves quantificational; tropes are fully specific.

The tropes that the quantificational properties quantify over are tropes that are instances of the base condition. For example, the tropes in the adjectival concept of dirty will be the tropes that include some 'dirtiness trope' (tropes whose bearer is 'covered with dirt'). The trope type scale of dirty then ranges from tropes including some minimal dirtiness trope to tropes that are themselves dirtiness tropes. Thus, the adjectival concept of dirty will be as follows, where $D$ is the property of instantiating the base condition:

$$
\mathrm{f}(\operatorname{dirty})(\mathrm{w}, \mathrm{i})=\left\{\mathrm{t} \mid \exists \mathrm{d}\left(\mathrm{t}=\mathrm{f}\left(\mathrm{d}, \lambda \mathrm{x}\left[\exists \mathrm{x}^{\prime} \exists \mathrm{t}^{\prime}\left(\mathrm{x}^{\prime}<\mathrm{x} \& \mathrm{D}\left(\mathrm{t}^{\prime}\right) \& \mathrm{~B}\left(\mathrm{x}^{\prime}, \mathrm{t}^{\prime}\right)\right)\right], \mathrm{w}, \mathrm{i}\right)\right\}\right.
$$

Thus, a trope in the content of dirty is an instance of the property of having a part that is a bearer of a dirtiness trope, that is, it is a trope whose bearer has a part that is a bearer of a dirtiness trope.

The tropes described by dirty are ordered according to the ordering of the tropes instantiating the base conditions that are included in them, or more precisely according to the ordering of the extents of the bearers of the latter tropes:

\section{(44) Trope ordering with partial adjectives}

For a partial adjective $A$ with a base condition $\mathrm{D}$, the set of worlds $\mathrm{W}$, and the set of times $I$, for any $w \in W, i \in I$, for any $t, t^{\prime} \in f(A)(w, i)$, $\mathrm{t} \leq_{\mathrm{A}} \mathrm{t}^{\prime}$ iff for any maximal tropes $\mathrm{t}^{\prime \prime}$ and $\mathrm{t}^{\prime \prime \prime}$ such that $\mathrm{D}\left(\mathrm{t}^{\prime \prime}\right), \mathrm{D}\left(\mathrm{t}^{\prime \prime \prime}\right)$, for any $\mathrm{d}^{\prime \prime}, \mathrm{d}^{\prime \prime \prime}$, such that $\mathrm{B}\left(\mathrm{d}^{\prime \prime}, \mathrm{t}^{\prime \prime}\right)$ and $\mathrm{B}\left(\mathrm{d}^{\prime \prime \prime}, \mathrm{t}^{\prime \prime \prime}\right)$, $\operatorname{ext}\left(\mathrm{d}^{\prime \prime}\right) \leq \operatorname{ext}\left(\mathrm{d}^{\prime \prime \prime}\right)$.

The minimum of the trope-type scale determined by dirty will consist in tropes containing a minimal trope of dirtiness (that is, a dirtiness trope with a minimal bearer) and the maximum in tropes that just are tropes of dirtiness. The standard of 
the content of dirty in a context may be just any trope type interval. This is the reason why Inference to the Positive is valid.

The tropes described by clean will be instances of the property of having a part that is not a bearer of a dirtiness trope:

$$
\mathrm{f}(\text { clean })(\mathrm{w}, \mathrm{i})=\left\{\mathrm{t} \mid \exists \mathrm{d}\left(\mathrm{t}=\mathrm{f}\left(\mathrm{d}, \lambda \mathrm{x}\left[\exists \mathrm{x}^{\prime} \neg \exists \mathrm{t}^{\prime}\left(\mathrm{x}^{\prime}<\mathrm{x} \& \mathrm{D}\left(\mathrm{t}^{\prime}\right) \& \mathrm{~B}\left(\mathrm{x}^{\prime}, \mathrm{t}^{\prime}\right)\right)\right], \mathrm{w}, \mathrm{i}\right)\right)\right\}
$$

These tropes will be inversely ordered to the ordering of the tropes instantiating the base condition, that is, roughly, a trope $t$ will exceed a trope $t$ ' in cleanliness just in case the maximal dirtiness trope $t$ contains is smaller than the maximal dirtiness trope t' contains. More generally, for two tropes $t$ and $t$ ' in the adjectival concept of clean, we have the following ordering:

\section{Trope ordering with total adjectives}

For a total adjective $A$ with a base condition $D, t \leq_{A} t^{\prime}$ iff for any maximal tropes $\mathrm{t}^{\prime \prime}, \mathrm{t}^{\prime \prime \prime}, \mathrm{t}^{\prime \prime}<\mathrm{t}$ and $\mathrm{t}^{\prime \prime \prime}<\mathrm{t}^{\prime}$ such that $\mathrm{D}\left(\mathrm{t}^{\prime \prime}\right), \mathrm{D}\left(\mathrm{t}^{\prime \prime \prime}\right)$, for any $\mathrm{d}^{\prime \prime}$ and $\mathrm{d}^{\prime \prime \prime}$ such that $B\left(d^{\prime \prime}, t^{\prime \prime}\right)$ and $B\left(d^{\prime \prime \prime}, t^{\prime \prime \prime}\right)$, ext $\left(d^{\prime \prime \prime}\right) \leq \operatorname{ext}\left(d^{\prime \prime}\right)$.

The minimum of the trope type scale of clean is a trope type all of whose instances have only a minimal non-dirtiness trope as part and the maximum is a trope type all of whose instances have only parts that fail to be dirtiness tropes. The standard for clean is fixed differently than for dirty: it is fixed as a maximal trope type, which is why for clean Inference to the Positive does not go through (Kennedy 2007).

Given the two ways of fixing the standard for partial and total adjectives, the restrictions on almost and slightly can be explained just as within a degree-based analysis like Kennedy's (2007): if almost A holds of an entity $x$ in $w$ at it means that the trope in $f(A)(w, i)$ that has $x$ as its bearer is 'very close' to the standard trope of A (in the context). If slightly A holds of $\mathrm{x}$, then $x$ has as its bearer a trope in the lower range of the trope type scale of $f(\mathrm{~A})$.

The two different kinds of inferences available with plurals is accounted for too. Partial adjectives are true of an entity $d$ (such as a plurality) in case a part of $d$ is a bearer of a trope instantiating the base condition (such as some members of the plurality). By contrast, total adjectives are true of an entity $d$ in case all parts of $d$ (such as the members of the plurality) are not bearers of a trope instantiating the base condition.

We have seen that some adjective modifiers act as predicates of actual trope arguments of adjectives; others locate an actual trope on the trope type scale. It appears that this distinction is reflected in the syntax as well, namely in two different adverbial interrogative constructions with how. Depending on the syntactic position of how, how-interrogatives display two distinct readings: a 'qualitative' one, relating to a particular trope, and a 'quantitative' one, relating to the trope type scale. When how is sentence-initial and the adjective left in situ as in (47a) and (48a), a qualitative reading arises. By contrast, only a quantitative reading is possible if the adjective is moved to sentence-initial position together with the modifier as in (47b) and (48b): 
(47) a. It was surprising how John is talented.

b. It was surprising how talented John is.

(48) a. It is admirable how she is disciplined.

b. It is admirable how disciplined she is.

(47a) expresses surprise at the ways in which John is talented, at the nature of a particular trope. By contrast, (47b) expresses surprise at the extent to which John is talented, at the position of John's talent on the trope type scale. Similarly for (48).

\section{Degree phrases and degree tropes}

Let us now turn to adjectives like small and tall, or heavy and light, which allow for degree phrases in differential comparatives (differential degree-phrases) and are associated with an established measure system. Let me call those adjectives measure-related adjectives. Recall that measure-related adjectives sometimes only allow for degree phrases with the positive. Degree-phrases obviously require incorporating degrees into the trope-based analysis of adjectives. Note that the trope-based analysis does not claim that natural language never makes reference to degrees, but only that it makes reference to tropes rather than degrees when there is no explicit reference to degrees or some other sort of specific semantic evidence for degrees.

Three generalizations about measure-related adjectives have been established in the literature:

[1] Inference to the Positive is invalid for both positive and negative measurerelated adjectives, as seen in the invalidity of the following inferences:

(49) a. John is taller than Mary.

John is tall and Mary is tall.

b. John is shorter than Mary.

John is short and Mary is short.

[2] Both positive and negative measure-related adjectives allow for differential degree phrases:

(50) a. John is $2 \mathrm{~cm}$ taller than Mary.

b. Mary is $2 \mathrm{~cm}$ shorter than John.

[3] Only positive measure-related adjectives allow for degree phrases in the positive form:

(51) a. John is two meters tall.

b. *John is two meters short. 
The first generalization, the invalidity of Inference to the Positive, follows already from the analysis of the positive and the comparative of relative adjectives that was presented, given that measure-related adjectives are relative adjectives. Relative adjectives in the positive describe relations between tropes and standards, whereas in the comparative they describe orderings among tropes.

How can the fact that comparatives of measure-related adjectives allow for differential degree-phrases be accounted for on the trope-based analysis? On the tropebased analysis, degrees are naturally assigned to tropes, rather than individuals. More precisely, a measurement of a trope $t$ consists in applying a measure function to $t$ and a standard $m$ and mapping them to the number of exact copies of $m$ whose concatenation approximates $t$ (cf. Klein 1991). A measure function in turn presupposes a function $g$ from concatenations of copies of the standard to real numbers:

\section{Trope measurement}

For a set $\mathrm{M}(\mathrm{m})$ of an infinite number of exact copies of a standard $\mathrm{m}$, and the set of real numbers $\mathrm{R}$, if $\mathrm{g}$ is a homomorphism from $(\mathrm{M}(\mathrm{m})$, $<, \bullet)$ to $(\mathrm{R}, \leq,+)$, that is, $\mathrm{g}(\mathrm{n} \bullet \mathrm{m})=\mathrm{g}(\mathrm{n})+\mathrm{g}(\mathrm{m})$ and $\mathrm{n} \leq \mathrm{m}, \neg \mathrm{m} \leq$ $\mathrm{n} \rightarrow \mathrm{g}(\mathrm{n})<\mathrm{g}(\mathrm{m})$, then a function $\mathrm{f}^{\prime}$ from $\mathrm{T} \times \mathrm{M}(\mathrm{m})$ to $\mathrm{R}$ is a measure function (measf) iff $\mathrm{f}^{\prime}(\mathrm{t}, \mathrm{m})=\mathrm{n}$, where for some $\mathrm{k}, \mathrm{km} \equiv \mathrm{t}$ and $\mathrm{g}(\mathrm{km})=\mathrm{n}$.

Here $k m$ is the concatenation of the standard $m$ with (k-1) copies of $m$ and $\equiv$ is the relation of approximation between tropes and concatenations of copies of the standard. (A standard in fact may be taken to be a kind of trope. Thus, a meter can be taken to be the set of length tropes of objects that are as long as the original 'standard meter'. Concatenation will then have to be defined for kinds of tropes.)

Differential degree phrases spell out the difference between the measurements of two tropes. They apply to both comparatives of positive and of negative adjectives:
a. John is $2 \mathrm{~cm}$ taller than Mary.
b. Mary is $2 \mathrm{~cm}$ shorter than John.

A differential measure phrase thus subtracts the greater one of the degrees measuring the two tropes from the smaller one. The constructional meaning of differential degree phrases with comparatives will then be as follows:

For a measure-related adjective A,

$<\mathrm{x}, \mathrm{y}>\in\left[\right.$ two meters $^{\mathrm{w}, \mathrm{i}}\left([\mathrm{A}-e r]^{\mathrm{w}, \mathrm{i}}\right)$ iff $\exists \mathrm{t} \exists \mathrm{t}^{\prime}\left(\mathrm{t} \in \mathrm{f}(\mathrm{A})(\mathrm{w}, \mathrm{i}) \& \mathrm{t}^{\prime} \in \mathrm{f}(\mathrm{A})(\mathrm{w}, \mathrm{i})\right.$

$\left.\& \mathrm{~B}(\mathrm{x}, \mathrm{t}) \& \mathrm{~B}\left(\mathrm{y}, \mathrm{t}^{\prime}\right) \& \max \left(\left\{\mathrm{f}^{\prime}(\mathrm{t}, \mathrm{m}), \mathrm{f}^{\prime}\left(\mathrm{t}^{\prime}, \mathrm{m}\right)\right\}\right)-\min \left(\left\{\mathrm{f}^{\prime}(\mathrm{t}, \mathrm{m}), \mathrm{f}^{\prime}\left(\mathrm{t}^{\prime}, \mathrm{m}\right)\right\}\right)=2\right)$, where $\mathrm{f}^{\prime}$ is a measure function and $m$ the standard 'meter'.

Since both positive and negative adjectives in the comparative denote relations between simple tropes, the constructional meaning of measure phrase modifiers can apply in the same way.

The trope-based analysis allows for a new explanation for why negative and excessive adjectives do not allow for degree phrases. For that purpose it is revealing 
to take a closer look at nominalizations and the acceptability of degree phrases with nominalizations. Two kinds of nominalizations need to be distinguished: positive nominalizations and absolute nominalizations:

[1] positive nominalizations: tallness, shortness, heaviness, lightness, wideness, narrowness

[2] absolute nominalizations: height, weight, width, length

Positive nominalizations are so-called because they are obviously derived from the positive form of the adjective: If John's tallness exists, then John is tall, and if John's smallness exists, then John is small. Absolute nominalizations, by contrast, are not tied to the positive form: the stick's length exists even if the stick is not long, and the building's height exists even if the building is not high. Positive nominalizations imply that the individual has the property at least to the extent of the standard. Absolute nominalizations, by contrast, have no such implications. To facilitate terminology, I will also call the NPs with positive or absolute nominalizations as head, such as Mary's tallness and John's heaviness, 'positive nominalizations' and NPs with absolute nominalizations as head, such as Mary's height and John's weight, 'absolute nominalizations'.

The crucial observation is that positive nominalizations do not allow for degree phrases as predicates, whereas absolute nominalizations do:
a. *John's tallness / shortness is 2 meters.
b. *John's enormousness is 2 meters.
c. John's height is two meters.

(56) a. *John's heaviness / lightness is 100 kilos.

b. John's weight is 100 kilos.
a. *The box's wideness is one meter.
b. *The canal's narrowness is one meter.
c. The box's length / width is one meter.

A related observation is that absolute nominalizations, unlike positive ones, accept degree phrase modifiers (Bierwisch 1987, p. 117):

a. The stick has a length of ten meters.

b. \# The stick has a shortness of ten meters.
a. The canal has a width of two meters.
b. \# The canal has a narrowness of two meters.

Negative and excessive adjectives, such as shortness, narrowness, and enormousness, always yield positive nominalizations. Positive adjectives may form the basis of both positive and absolute nominalizations, and thus an adjective allowing for degree modifiers does not automatically yield an absolute nominalization. For example, in English, it is height not tallness, and weight not heaviness that acts as an absolute nominalization. 
The two kinds of nominalizations can be related to two ways of using the positive form of adjectives: the positive with a degree phrase corresponds to the absolute nominalization; the positive without a degree phrase to the positive nominalization. That is, height is semantically the nominalization of tall with a degree phrase (two meters tall), whereas tallness is semantically the nominalization of tall without a degree phrase. Weight is semantically the nominalization of heavy, even though, formally, heavy in English does not take degree phrases. Thus, absolute nominalizations correspond to those adjectives that may take degree phrases in some language and positive nominalizations to those that don't take degree phrases in any language. Whereas for two polar adjectives, the positive adjective will be chosen whenever degrees are to be specified, for forming a corresponding absolute nominalization, in general, either the positive of the same or a related pair of polar adjectives is used or else the nominalization of a corresponding measure verb (such as weigh for deriving weight). Absolute nominalizations, it appears, are never formed on the basis of a negative or excessive adjective.

Absolute nominalizations such as John's weight, John's height, and the box's length are often considered terms that refer to degrees. This is mistaken, however. Various sorts of evidence show that absolute nominalizations refer to tropes.

First, the referents of absolute nominalizations can have certain properties that only tropes can have, namely perceptual and causal properties:

(60) a. I noticed John's weight

b. \# I noticed a hundred kilos.

(61) a. John's weight caused the beam to break.

b. \# A hundred kilos caused the beam to break.

Tropes but not abstract entities like degrees can be the objects of perception and of causal relations, at least on the most common philosophical views.

Second, absolute nominalizations do not allow for the degrees they are supposed to refer to to be made explicit, if degrees are just numbers or intervals (as they are generally taken to be in the semantic literature):

a. *John's weight is the number one hundred.
b. *John's weight is Mary's height, namely fifty.

But even if degrees are not just numbers, the sentence below should be acceptable if absolute nominalizations refer to degrees:

*John's height is the same degree as Mary's height.

A further problem for the view that absolute nominalizations refer to degrees is that the referents of absolute nominalizations are also the targets of measurements and therefore cannot be degrees themselves:

(64) John measured Mary's height. 
If absolute nominalizations do not refer to degrees, this means that (65) is not an identity statement, but rather is to be understood as a subject-predicate sentence (or perhaps a specificational sentence):

John's height is two meters.

That (65) is not an identity statement goes along with the view that degree phrases have in fact a nonreferential status (Rizzi 1999). Note also that in some languages, for example German, the verb 'amounts to' rather than the copula may be used in a sentence like (65), which would be entirely unexpected if absolute nominalizations referred to degrees:

(66) Hans' Groesse betraegt 2 meter.

'John's height amounts to two meters.'

Another argument against absolute nominalizations referring to degrees is that the referent of absolute nominalizations is not specific as to the kind of measurement (kind of standard) used. This can be seen from disjunctions as in (67):

John's height is 180 centimeters or 5 feet and 9 inches.

It is also shown by the observation that the question in (68a) is distinct from the question in (68b), that is, (68a) does not presuppose a decision as to which measure system is used:

(68) a. What is John's height?

b. What is John's height in centimeters?

All those data support the view that absolute nominalizations refer to tropes, namely quantitative tropes, instances of quantities like height, weight, and age. Quantitative tropes are qualitatively simple, but quantitatively additive: any part of a quantity (exactly) resembles the quantity qualitatively, but differs from it quantitatively (Campbell 1990, p. 86). The qualitative simplicity of quantities can be seen from identity statements such as $(69 a, b, c)$, which express qualitative (not numerical) identity:

(69) a. John's height is the same as Mary's.

b. John's weight is the same as Bill's.

c. John's age is the same as Mary's age.

Measure phrases with the copula as in (65) thus need to be analysed in a different way than as providing arguments of the identity predicate. Assuming then that (65) is a subject-predicate sentence and setting aside the issue of a compositional semantic analysis, the complex predicate is two meters can be taken to express the property that holds of a trope $t$ iff applying a measure function (measf) to $t$ and the standard meter $m$ yields 2 : 
(70) $[\text { is two meters }]^{\mathrm{w}, \mathrm{i}}=\left\{\mathrm{t} \mid \exists \mathrm{f}^{\prime}\left(\operatorname{measf}\left(\mathrm{f}^{\prime}\right) \& \mathrm{f}^{\prime}(\mathrm{t}, \mathrm{m})=2\right)\right\}$, where $\mathrm{m}$ is the standard 'meter'.

Quantitative tropes fulfil another semantic role besides being referents of absolute nominalizations. They should also be considered the trope arguments of adjectives in the positive when they take a degree phrase as modifier. The denotation of an adjective with a degree phrase will then be as follows:

$[\text { two meters long }]^{\mathrm{w}, \mathrm{i}}=\left\{<\mathrm{t}, \mathrm{x}>\mid<\mathrm{t}, \mathrm{x}>\in[\text { long }]^{\mathrm{w}, \mathrm{i}} \& \exists \mathrm{f}^{\prime}\left(\right.\right.$ measf $\left(\mathrm{f}^{\prime}\right) \&$ $\left.\left.\mathrm{f}^{\prime}(\mathrm{t}, \mathrm{m})=2\right)\right\}$, where $m$ is the standard 'meter'.

Since positive adjectives in the absence of a degree phrase imply that the trope described be above the standard, positive adjectives should denote a relation between quantitative tropes and individuals only if they syntactically occur with a degree phrase. This means that certain positive adjectives, such as long, high, and wide in English, are in fact ambiguous (or rather polysemous). One version of the adjective syntactically selects a degree phrase and semantically takes quantitative tropes as arguments. Another, homophonous version does not allow for degree phrases and describes a comparison of a quantitative trope with the standard (in a way to be made precise shortly). The latter should be taken as the standard meaning of the positive form, since allowing for degree phrases is a special lexical feature of only certain adjectives.

Why do positive nominalizations not allow for degree predicates? The reason must be that positive nominalizations do not refer to the same simple tropes as absolute nominalizations. In particular, positive nominalizations do not just refer to quantitative tropes on the upper part of the relevant trope type scale.

Trope theory offers the following alternative for what positive nominalizations refer to: positive nominalizations refer to relational tropes, instances of the relation 'is greater than or equal to', instantiated by the quantitative trope and the standard. This would immediately explain why degree phrases are not applicable with positive nominalizations: measurement is defined only for simple, quantitative tropes, but not for relational tropes with the simple tropes and the standard as bearers.

Such relational tropes cannot quite be the entities that positive nominalizations refer to, though. Relational tropes with a simple trope and a standard as bearers should have certain properties inherited from both bearers. For example, a relational trope is concrete just in case its bearers are concrete. A standard, being a type, is not concrete, and thus the relational trope should not be either. But the referent of a positive nominalization such as John's tallness is as concrete as John (it can be observed and have causal effects). Also the location of the referent of a positive nominalization is, intuitively, quite simply the location of the simple trope. But if the referent was a relational trope with a simple trope and a standard as bearers, it would be much more problematic what the location of the referent should be.

There is another alternative available within trope theory: conceiving of the referent of a positive nominalization as a nonrelational trope instantiating a complex object-dependent property, namely the property of meeting or exceeding the 
standard. Such a trope differs from the relational trope at least by inheriting the concrete/abstract status as well as its spatio-temporal location only from the one bearer, the particular quantitative trope, not the standard, which is not a bearer of the trope. Let us call such tropes quasi-relational tropes. Quasi-relational tropes are also plausible candidates for the referents of nominalizations such as John's fatherhood and Mary's love for Bill (as opposed to the love between Mary and Bill).

The denotation of a positive nominalization of an adjective $\mathrm{A}, \mathrm{A}_{\text {nom-pos }}$, can then be given as below:

$$
\begin{aligned}
& {\left[\mathrm{A}_{\text {nom-pos }}\right]^{\mathrm{c}, \mathrm{w}, \mathrm{i}}=\left\{<\mathrm{t}, \mathrm{x}>\mid \exists \mathrm{t}^{\prime}\left(\mathrm{B}\left(\mathrm{x}, \mathrm{t}^{\prime}\right) \& \mathrm{t}^{\prime} \in \mathrm{c}(\mathrm{A})(\mathrm{w}, \mathrm{i}) \& \mathrm{t}=\mathrm{f}\left(\mathrm{t}^{\prime}, \lambda \mathrm{y}\left[\mathrm{y} \geq_{\mathrm{A}}\right.\right.\right.\right.} \\
& \quad \text { standard }(\mathrm{c}(\mathrm{A}), \mathrm{c})], \mathrm{w}, \mathrm{i}))\}
\end{aligned}
$$

Quasi-relational tropes are also suitable as trope arguments of negative and excessive adjectives in the positive form. Here the tropes would be instances of the properties of being 'less than' the standard and being 'much greater than' the standard. Thus, a negative adjective like small in the positive form will have the denotation in (73):

$$
\begin{aligned}
& {[\text { small }]^{\mathrm{c}, \mathrm{w}, \mathrm{i}}=\left\{<\mathrm{t}, \mathrm{x}>\mid \exists \mathrm{t}^{\prime}\left(\mathrm{B}\left(\mathrm{x}, \mathrm{t}^{\prime}\right) \& \mathrm{t}^{\prime} \in \mathrm{f}(\text { small })(\mathrm{w}, \mathrm{i}) \&\right.\right.} \\
& \left.\left.\mathrm{t}=\mathrm{f}\left(\mathrm{t}^{\prime}, \lambda \mathrm{y}\left[\mathrm{y} \leq_{\text {small }} \operatorname{standard}(\mathrm{c}(\text { small }), \mathrm{c}) \& \neg \mathrm{s}(\mathrm{c}, \mathrm{f}(\text { small })) \leq_{\text {small }} \mathrm{y}\right], \mathrm{w}, \mathrm{i}\right)\right)\right\}
\end{aligned}
$$

This account straightforwardly explains why negative and excessive adjectives do not take degree phrases as modifiers: measurement is not defined for quasirelational tropes.

Positive adjectives in the positive form, when occurring without degree phrase, also take quasi-relational tropes as arguments. When the adjective has a lexical variant that allows and in fact requires a degree phrase, then that variant takes simple tropes, not quasi-relational tropes as arguments. I will consider the obligatory presence of a degree modifier with the second variant simply a syntactic selectional requirement of the adjective (though there might perhaps be alternative pragmatic explanations, a discussion of which should await another occasion).

There is one further difference between absolute and positive nominalizations, which is that unlike absolute nominalizations like John's height, positive nominalizations like John's tallness do not seem to have a variant referring to an entity with variable trope manifestations:
a. John's height has changed.
b. ? John's tallness has changed.

Given that John's tallness refers to a quasi-relational trope, this difference can be explained straightforwardly. John's tallness refers to a quasi-relational trope which is a height trope reduced to its aspect of exceeding the contextual standard. Clearly, two tallness tropes of John at different times are 'very similar' even if they involve quite different height tropes. Thus, at those two times John's tallness will hardly have changed even though John's height will have. Thus (74a) will be true, but (74b) will in fact come out false, which after reflection seems correct. 
Quasi-relational tropes bear some resemblance to order-constituted tropes. In fact, if the ordering were to include the relation of the trope to the standard, then an order-constituted trope would be another candidate for a referent of a positive nominalization. On such an account, 'John's weakness' would be constituted by John's physical condition as well as its being less than the standard and greater than or less than all the other physical conditions of the same sort:

$$
\begin{aligned}
& {[\text { John's weakness }]^{\mathrm{c}, \mathrm{w}, \mathrm{i}}=\mathrm{c}(\{\mathrm{t} \mid \mathrm{t} \in \mathrm{c}(\text { weak })(\mathrm{w}, \mathrm{i}) \& \mathrm{~B}(\mathrm{John}, \mathrm{t})\}} \\
& \cup\left\{\mathrm{r} \mid \mathrm{r}=\mathrm{f}(\mathrm{t}, \operatorname{standard}(\mathrm{c}(\text { weak }), \mathrm{c}), \leq, \mathrm{w}, \mathrm{i}) \mathrm{v} \exists \mathrm{t}^{\prime}\left(\mathrm{t}^{\prime} \in \mathrm{f}(\text { weak })(\mathrm{w}, \mathrm{i})\right.\right. \\
& \left.\left.\left.\&\left(\mathrm{r}=\mathrm{f}\left(\mathrm{t}, \mathrm{t}^{\prime}, \leq, \mathrm{w}, \mathrm{i}\right) \vee \mathrm{r}=\mathrm{f}\left(\mathrm{t}^{\prime}, \mathrm{t}, \leq, \mathrm{w}, \mathrm{i}\right)\right)\right)\right\}\right)
\end{aligned}
$$

This account is suited for John's weakness, because John's weakness would not allow for degree predicates anyway. However, for at least some nominalizations of measure-related adjectives such as tallness or shortness, quasi-relational tropes as referents seem more appropriate. Exceed-predicates, which had motivated orderconstituted tropes, are not very suited with the latter (?? John's tallness exceeds / is greater than Bill's tallness), though they are fine with John's weakness (John's weakness exceeds Mary's weakness). We may then conclude that both quasi-relational tropes and order-constituted tropes should be admitted for the semantics of adjective nominalizations.

\section{Comparative subdeletion}

We can now turn to the analysis of comparative subdeletion, which, as was mentioned, is one important empirical motivation for the trope-based analysis. The trope-based analysis provides a straightforward explanation of the restrictions on comparative subdeletion, such as seen in the contrast between (76a) and (76b), as opposed to the lack of contrast between (77a) and (77b):

(76) a. *John is happier than he is tall.

b. \# John is happier than Mary is sad.

(77) a. The door is wider than it is high.

b. The stick is longer than the door is high.

c. *The stick is heavier than it is high.

On the trope-based analysis, no appeal to a dimension or type of degree needs to be made to explain incommensurability and its absence in subdeletion constructions. What determines whether there will be incommensurability is whether the tropes being compared are of the same sort or not, that is, belong to a single adjectival concept.

A happiness trope and a height trope clearly cannot be compared as to which is greater than the other. More precisely, the comparative trope relation described by happy cannot compare a happiness trope and a height trope, but only two happiness tropes. The relation also cannot compare a happiness trope and a sadness trope. One 
might think that it can perhaps compare the intensity of happiness and of sadness. But this seems at least only marginally possible.

By contrast, a trope of an object's length and a trope of another object's width certainly are comparable, because they can be viewed as quantitative tropes of the very same sort, to which one and the same comparative relation can apply: an object's length and another object's width are both an object's linear extension, in one direction or another. Thus, (77a) involves two tropes of the same type: height and width, which are quantitative tropes of linear extension, differing only in the direction of that extension. (77b) also involves two tropes of the same type, length and height, which are again linear extension tropes differing in the direction of the linear extent. In (77a) the direction is absolute and in (77b) relative to the proportions of the object. In $(77 \mathrm{c})$ we see that two quantitative tropes cannot be compared if they are of different kinds.

There is striking evidence that the possibility of subdeletion depends indeed on the kinds of tropes involved. This is that roughly the same observations about commensurability can be made with explicit nominalizations:

(78) a. *John's happiness exceeds John's tallness.

b. ? John's happiness exceeds Mary's sadness.

c. The door's width exceeds the door's height.

d. The stick's length exceeds the door's height.

e. *The stick's weight exceeds the stick's length.

An object's width, height, and length are tropes of the same type because they are all instantiations of linear extendedness in an object. A given object may of course have several linear extensions, which can be selected relative to the proportions of the object or relative to the surrounding space. In that case, one and the same object is the bearer of several tropes instantiating a single property (linear extension). There is thus no single trope that corresponds to an object, the property of linear extendedness, a world, and a time, but several. For such a partial characterization of a trope, I will use a two-place predicate LinExt, which relates a trope to the object whose linear extension it is, at a world $w$ and a time $i$. A complete specification of a linear extension trope will require a further qualification, for example, for a trope of height the property of being vertical and for a trope of width the property of being horizontal. The denotations of height and width can thus be given as follows:

$$
\begin{aligned}
& \text { a. }[\text { height }]^{\mathrm{w}, \mathrm{i}}=\{<\mathrm{t}, \mathrm{x}>\mid \operatorname{LinExt}(\mathrm{t}, \mathrm{x}, \mathrm{w}, \mathrm{i}) \& \operatorname{vertical}(\mathrm{t}, \mathrm{w}, \mathrm{i})\} \\
& \text { b. }[\text { width }]^{\mathrm{w}, \mathrm{i}}=\{<\mathrm{t}, \mathrm{x}>\mid \operatorname{LinExt}(\mathrm{t}, \mathrm{x}, \mathrm{w}, \mathrm{i}) \& \operatorname{horizontal}(\mathrm{t}, \mathrm{w}, \mathrm{i})\}
\end{aligned}
$$

The exceed-predicates in $(78 \mathrm{c}, \mathrm{d})$ then compare two tropes of linear extension.

To account for comparative subdeletion, we need to distinguish between phrasal comparatives and sentential comparatives, which includes comparative subdeletion. In the phrasal comparative construction, as in the door is wider than the frame, the meaning of wider relates any two entities that are bearers of tropes that are linear extents and horizontal, as in (80): 
(80) $\quad[\text { wider }]^{\mathrm{w}, \mathrm{i}}=\left\{<\mathrm{x}, \mathrm{y}>\mid \exists \mathrm{t} \exists \mathrm{t}^{\prime}(\mathrm{B}(\mathrm{x}, \mathrm{t}) \& \operatorname{LinExt}(\mathrm{t}, \mathrm{x}, \mathrm{w}, \mathrm{i}) \& \operatorname{horizontal}(\mathrm{t}, \mathrm{w}, \mathrm{i}) \&\right.$ $\left.\left.\mathrm{B}\left(\mathrm{x}, \mathrm{t}^{\prime}\right) \& \operatorname{LinExt}\left(\mathrm{t}^{\prime}, \mathrm{x}, \mathrm{w}, \mathrm{i}\right) \& \operatorname{horizontal}\left(\mathrm{t}^{\prime}, \mathrm{w}, \mathrm{i}\right)\right)\right\}$

This needs to be distinguished from the meaning of wider when it occurs in sentential comparatives, as in (81a). Here the second argument can be any linear extension trope, as specified by the (explicit or silent) adjective in the than-clauses, as in the analysis of (81a) in (81b):

(81) a. The door is wider than it is high.

b. wider(the door, $\imath \mathrm{t}$ [high(t, the door)] )

Note that the adjective in the than-clause must occur with the meaning it has when it takes simple tropes as arguments (the meaning it has when taking degree phrases as modifiers), rather than quasi-relational tropes.

Besides the restriction to the same kind of trope, there is another restriction on comparative subdeletion that the trope-based analysis can straightforwardly explain, namely a restriction against negative adjectives entering the comparative subdeletion construction (cf. Bierwisch 1987): ${ }^{20}$

(82) a. *John is shorter than the door is low.

b. *Mary is taller than John is short.

This simply follows from the fact that the trope arguments of negative adjectives are quasi-relational tropes and comparatives just do not take quasi-relational tropes as arguments.

This also holds for excessive adjectives, of course, which resist comparative subdeletion as well:

(83) a. *Mary is even taller than John is huge.

b. *The dog is bigger than the cat is enormous.

There is a different type of comparative subdeletion, involving two polar adjectives:

(84) a. John is as obese as Mary is slim.

b. John drives as carefully as Mary drives carelessly.

My watch is as slow as yours is fast.

As Kennedy (2001) notes, what is being compared here is the distance (in two different directions) to a standard.

The trope-based analysis provides the following novel account of such comparatives. What is compared, for example, in (84a) is the instantiation of the

${ }^{20}$ Here I adopt Bierwisch's (1987) generalization, but see Kennedy (2001) for a different view. 
disjunctive relation $\leq \mathrm{v} \geq$ ('is less than or exceeds') that obtains between John's weight and the standard and an instance of the same relation obtaining between Mary's weight and the standard. That is, (84a) involves a comparison of two relational tropes instantiating a relation more general than the $\leq$-relation or the Z-relation, namely its disjunction, a relation that holds between two entities just in case one exceeds the other. This interpretation is obtained by mapping the quasi-relational trope that is the instantiation of the $\leq$-relation relative to the standard to the instantiation of the $\leq \mathrm{v} \geq$-relation relative to the standard.

There is another type of comparative construction that gives additional motivation for the trope-based account. This comparative construction, briefly discussed in Klein (1991), is the one in (86):

(86) a. Mary is more sad than angry.

b. The table is more decorative than it is useful.

c. John's manner was more elegant than his manner was convincing.

This comparative construction is formally distinct from the standard comparative (cf. Klein 1991). For example, the use of more instead of the morpheme -er in (86a, b, c) is obligatory. The relevant interpretation is available only in (86a), but not in (87):

* Mary is sadder than angry.

While there seems to be no proposal of a semantic analysis in the literature, the trope-based analysis allows for the following account. (86a) is about a single trope, a state or rather trope of Mary's, and this trope is a better instantiation of sadness than it is of anger. What happens here is that two relational tropes are compared: the instantiation of sadness in Mary and the instantiation of anger in Mary. Similarly, (86b) is about the overall positive quality of the table, and it is said that it is a better instantiation of decorativeness than of usefulness. This gradable property of being a better instantiation of a concept $\mathrm{P}$ than of a concept $\mathrm{Q}$ may be understood in various ways: it may mean that the entity is better evaluated as falling under $Q$ than as falling under $\mathrm{P}$ or that it is a bearer of a trope that is closer to the P-trope type on some given trope type scale than it is to a Q-trope type on some other trope type scale. If we take Inst to be a gradable relation of instantiation, then (86a) can be analysed as follows, using an operation of maximal trope formation max:

$$
\begin{aligned}
& \imath \mathrm{t}^{\prime}\left[\mathrm{t}^{\prime}=\mathrm{f}\left(\max \mathrm{t}\left[\mathrm{P}_{\mathrm{c}}(\mathrm{t}, \mathrm{w}, \mathrm{i}) \& \mathrm{~B}(\text { Mary, } \mathrm{t})\right], \lambda \mathrm{x}\left[\exists \mathrm{t}\left(<\mathrm{t}, \mathrm{x}>\in\left[\text { happy }_{\mathrm{pos}}\right]^{\mathrm{c}, \mathrm{w}, \mathrm{i}}\right],\right.\right.\right. \\
& \text { Inst, w, i) }] \geq \imath \mathrm{t}^{\prime \prime}\left[\mathrm{t}^{\prime \prime}=\mathrm{f}\left(\max \mathrm{t}\left[\mathrm{P}_{\mathrm{c}}(\mathrm{t}, \mathrm{w}, \mathrm{i}) \& \mathrm{~B}(\text { Mary, } \mathrm{t})\right], \lambda \mathrm{x}[\exists \mathrm{t}(<\mathrm{t}, \mathrm{x}>\epsilon\right.\right. \\
& \left.\left.\left.\left[\operatorname{sad}_{\text {pos }}\right]^{\mathrm{c}, \mathrm{w}, \mathrm{i}}\right], \text { Inst, w, i }\right)\right]
\end{aligned}
$$

That is, according to (88), (86a) claims that there is a better instantiation of happiness in the maximal contextually relevant quality of Mary than there is of sadness. Here the instantiation relation actually relates a trope to the property expressed by the positive. This is required because the same comparative construction is possible 
with relative adjectives involving a context-dependent standard (Mary is more short than tall). That the evaluation of the positive form of the adjective is crucial in the semantic analysis of such comparatives corresponds to the fact that the positive form occurs separately from the comparative morpheme more.

\section{Reference to degrees, extents, and numbers}

The kinds of tropes considered so far consisted in more or less complex qualitative aspects of individuals. Natural language also permits reference to more abstract tropes, with constructions that have generally been held to refer to purely abstract objects.

First, there are constructions like the degree of Mary's unhappiness and the extent of Mary's anger. On the standard view, those terms would refer to abstract objects that are 'degrees'. There is evidence, however, that they refer to tropes rather than purely abstract objects, namely the applicability of perceptual and causal predicates:

(89) a. John was shocked by the degree of Mary's unhappiness.

b. John had not noticed the extent of Mary's anger.

These observations also show that the entities in question cannot be types of tropes (lets say classes of equivalent unhappiness or classes of equivalent angers).

The tropes in question, degree tropes and extent tropes, are more abstract than tropes like Mary's unhappiness in that they involve abstracting from the particuliarities of the nature of the trope (the particular way unhappiness manifests itself in Mary), and instead focusing on the quantitative relation of the trope to others of the same sort, that is on the position of the trope on the trope scale. Thus, even if Mary's unhappiness is quite different in nature from John's, the corresponding degree tropes may be qualitatively identical:

(90) The degree of John's unhappiness is the same as the degree of Mary's unhappiness.

Two degree tropes that are obtained from different tropes $t$ and $t^{\prime}$ instantiating the concept of the same adjective A are exactly similar just in case $t \leq \mathrm{t}^{\prime}$ and $t^{\prime} \leq \mathrm{t}$.

Extent tropes differ from degree tropes in that they can be associated also with events, not just with (simple) tropes:

(91) a. the degree of Bill's astonishment

b. *the degree of Bill's astonishing Mary

(92) a. the extent of Bill's astonishment

b. *the extent of Bill's astonishing Mary

(93) a. the extent of Mary's activity

b. *the degree of Mary's activity 
Extent tropes are not ordered according to the relation expressed by the adjectival concept, but rather by independent criteria, such as the amount of causal effect, temporal duration, or the amount of effected change. But relative to such an ordering they involve the same abstraction from the qualitative nature of the trope or event in question. Extents are obviously what is compared in event comparatives, as in (94):

a. Mary has changed more than John.

b. Mary sang more than John.

Recall that event comparatives may compare events in various respects, which corresponds to the different ways of abstracting 'extents' from events.

Another construction that seems to make reference to abstract objects, but in fact refers to tropes is the construction the number of $\mathrm{N}$. The application of perceptual and causal predicates indicates that such terms refer to tropes of a certain sort:

(95) a. John noticed the number of women.

b. The small number of women caused Bill consternation.

Note also a range of number-specific predicates are not possible with such terms:

*the natural / prime / real number of women

The number of women is best seen as referring to a 'number trope', an entity that is the 'reduction' of a plurality of women to just 'how many they are'. Again this involves abstracting from the particular nature of the women and focusing just on them being so and so many cases of women.

Given this form of abstraction, two different number tropes, based on different kinds of pluralities, will be exactly similar just in case the one plurality has as many members as the other:

(97) The number of women is the same as the number of men.

Here the same as expresses again qualitative, not numerical identity. ${ }^{21}$

Another kind of abstraction that can be performed with tropes is the formation of hypothetical copies of (quantitative) tropes for the purpose of addition. This is achieved by using the expression times, as below:

(98) a. Sue is three times as clever as Mary.

b. Mary sang three times more than John.

c. There are three times more women than men.

\footnotetext{
21 Note that the property that defines number tropes has a different ontological status in regard to the bearer than properties usually have that define tropes: the property is an essential property of the plurality, rather than a property that the plurality instantiates only in certain circumstances (cf. Simons, to appear).
} 
The expression times, it appears, expresses an operation forming types of degree tropes in (98a), types of extent tropes in (98b), and types of number tropes in (98c). That the expression times itself involves a mapping from tropes to types of (quantitative) tropes is made transparent by the construction three times the cleverness of Mary.

The kind of abstraction involved in degree tropes, extent tropes, and number tropes is what Campbell (1990) calls hyperabstraction. Hyperabstraction yields tropes by abstracting from the particular natures of entities and focusing on their particuliarity only (being this or that). In the case of degree tropes, the focus is moreover on their quantitative relations to tropes of the same sort, in the case of extent tropes on their relations within an externally imposed ordering, and in the case of number tropes on their mere distinctness.

There is yet another kind of abstraction possible: abstracting from the particular choice of a bearer and thus obtaining a trope with an arbitrary bearer. In the case of number tropes this amounts to the construal of numbers in terms of Cantorian abstraction (Fine 1998).

\section{Comparison with predicative same and different}

Comparatives with same and different, as in (99) and (100), provide another piece of evidence for tropes:

(99) a. John is different from what he used to be.

b. John is the same as he always was.

(100) John writes differently than Mary does.

Comparatives with same and different exhibit numerous parallels with 'degree'comparatives, but there is hardly a reason to think that they involve degrees.

Same and different as predicates as in (99) do not express distinctness or identity of individuals, but rather express qualitative identity (exact similarity) or qualitative difference among tropes. In (99a) and (99b) these will be maximal tropes having John as bearer that instantiate contextually relevant properties. In (100) these will be maximal tropes having events (including habits) as bearers.

(99a) thus roughly means 'the maximal trope involving John now is qualitatively distinct from the maximal trope involving John in the past' and (99b) 'the maximal trope involving John now is (qualitatively) the same as the one involving John in the past'. Similarly, (100) means 'the maximal trope involving John's writing is (qualitatively) distinct from the maximal trope involving Mary's writing'.

Thus, (99b) can be analysed along the lines of (101):

(101) The maximal trope involving John, meeting a contextually given condition, is the same as the maximal trope involving John meeting the same condition at any previous relevant time. 
This, simplified, corresponds to the formal analysis in (102), where $\mathrm{P}_{\mathrm{c}}$ is a contextual restriction on relevant tropes, $\sim$ the relation of exact similarity, and $<$ the relation of temporal precedence: ${ }^{22}$

(102) $\max t\left[\mathrm{P}_{\mathrm{c}}(\mathrm{t}) \& \mathrm{~B}(\mathrm{John}, \mathrm{t}) \& \operatorname{at}(\mathrm{t}, \mathrm{i})\right] \sim \max \mathrm{t}\left[\mathrm{P}_{\mathrm{c}}(\mathrm{t}) \& \mathrm{~B}(\mathrm{John}, \mathrm{t}) \&\right.$ at $\left.\left.\left.\left(\mathrm{t}, \mathrm{i}^{\prime}\right)\right)\right]\right)$ for any time $i^{\prime}$ such that $i^{\prime}<i$.

Here it is assumed that the same trope may be an instance of various properties, not just a single one.

Predicative same as in (99b) $\left(\right.$ same $\left._{2}\right)$ has a somewhat different meaning than the same expressing exact similarity as discussed earlier. The meaning of same in (99b) is based on the relation of exact similarity $(\sim)$, but it is a relation between individuals and tropes:

$$
\left[\text { same }_{2}\right]^{\mathrm{w}, \mathrm{i}}=\left\{<\mathrm{d}, \mathrm{t}>\mid \max \mathrm{t}^{\prime}\left[\mathrm{P}_{\mathrm{c}}\left(\mathrm{t}^{\prime}\right) \& \mathrm{~B}\left(\mathrm{John}, \mathrm{t}^{\prime}\right) \& \operatorname{at}\left(\mathrm{t}^{\prime}, \mathrm{i}\right)\right] \sim \mathrm{t}\right\}
$$

This will also be the sort of meaning of differently in (100), with events rather than individuals acting as first arguments. ${ }^{23}$

\section{Conclusion and further remarks}

The main overall empirical support for the trope-based analysis comes from the observation that various important generalizations about positive and comparative adjectives are directly reflected in corresponding generalizations about adjective nominalizations, that is, in generalization about trope-referring terms. The paper thus covers a wider empirical domain than degree-based analyses or the older analyses of Kamp (1975) and Klein (1980) that do without degrees.

\footnotetext{
22 See Footnote 9.

23 Alrenga (to appear), using the standard formal semantic arsenal of properties and individuals, proposes an analysis according to which same and different in $(99,100)$ act as quantifiers over properties. (99a) is analysed roughly as 'the set of contextually relevant properties John has now is distinct from the set of contextually relevant properties John used to have in the past'. (99b) is analysed as 'the set of contextually relevant properties John has now is identical to the set of contextually relevant properties John always had'. There is no space here for a full discussion of Alrenga's analysis. Let me just mention one difficulty for it, and that is that this analysis of same / different-comparatives would have to assign same/ different in $(99,100)$ a very different meaning than same and different have in all other contexts, namely in which they mean sameness or distinctness, as in the examples below:
}

(1) a. John drives a mercedes. Mary drives the same car.

b. John and Mary met the same man.

c. John is the same man as the one we met yesterday.

Same and different in (1) clearly express sameness or difference among entities (qualitative or numerical) not the sharing or not sharing of contextually relevant properties. Note that the identity statement in (1c) is also a comparative construction, but clearly not quantifying over properties. 
The trope-based analysis of adjectival constructions that this paper has explored presents a certain ontological picture of abstract entities. Tropes are entities dependent on others, they depend on their bearer, but they are at the same time as real and concrete as their bearers. Tropes are more abstract than their bearers in the sense that tropes are entities that by nature are restricted to only some of the qualitative aspects of their bearers. This is often described in terms of a psychological process of abstraction: tropes are obtained from individuals by attending to only one quality of the individuals and abstracting from all the others. However, ontologically, this relation of abstraction simply means that tropes form greater similarity classes than their bearers: they are exactly similar to more tropes than their bearers are to other objects. Second-order tropes are even more abstract, being 'obtained' from first-order tropes by focusing on only one qualitative or quantitative aspect of them.

The possibility of describing tropes as the result of a mental operation of abstraction does not require a conceptualist view of the ontological status of tropes. Tropes exist entirely independently of whether a mental process of abstraction has been performed. A mental process of abstraction only aids recognition of already existing entities; it does not create them. But the possibility of describing tropes that way displays a major advantage of trope ontology for natural language semantics in general, as opposed to an ontology of purely abstract objects such as degrees (on a standard view of degrees). It is common in linguistic semantics to make rather generous use of abstract objects. Abstract objects, however, come with a range of long-debated philosophical problems. Two prominent problems are first, how we can have epistemic access to them (that is how can we have knowledge of abstract objects if they are not part of the empirical world), and second, how can abstract entities causally interact with other entities? By making use of tropes, these problems are avoided straightforwardly: tropes, if their bearers are concrete, are part of the empirical world and are both objects of perception and causally efficacious. The trope-based analysis thus goes along with a particular cognitive plausibility.

The use of tropes yields degrees of abstractness, but not by constructing or introducing entities entirely dissociated from concrete objects, but rather by admitting classes of entities that make up greater similarity classes. Thus even if objects $x$ and $y$ are quite dissimilar, the unusualness of $x$ and the unusualness of $y$ may be very similar and the redness of $x$ and the redness of $y$ may even be exactly similar, and even if the unusualness of $\mathrm{x}$ was quite different from the unusualness of $y$, the degree of unusualness of $x$ may be the same as the degree of the unusualness of $y$. The ontology involved in the semantics of adjectival constructions thus displays a range of successive stages of abstraction, involving 'abstract particulars' of various sorts, forming greater and greater similarity classes.

This contrasts sharply with the picture usually presupposed in formal semantics, namely that adjectival constructions involve purely abstract objects, both as implicit arguments and as referents of nominalizations and functional terms. Positive and comparative adjectival constructions, I have argued, do not involve abstract objects such as degrees, extents, and numbers. Even terms that apparently make explicit reference to such entities are in fact terms that refer to degree tropes, extent tropes, and number tropes, tropes that display a greater degree of abstraction than standard tropes. 
The trope-based analysis of course also has significant metaphysical plausibility in that it provides an account of co-extensional properties without recourse to possible objects. Possible tropes, though, are needed in special contexts, such as noninstantiated properties and contextual standards, intensional contexts (attitude contexts and conditionals), and finally trope-type scales, involving a possibly noninstantiated maximum or minimum.

Acknowledgements I would like to thank audiences at the University of Stuttgart, the University of Tübingen, the University of Chicago, the University of Tokyo, and the Amsterdam Colloquium 2006 for stimulating discussions as well as Chris Barker, Kit Fine, and Peter Simons for discussions of an earlier version of this paper.

\section{References}

Alrenga (to appear). Comparisons of similarity and difference. Proceedings of the workshop on the formal analysis of adjectives, Paris 7, Jussieu 2005.

Bacon, J. (1995). Universals and property instances - The alphabet of being. Oxford: Blackwell.

Beebee, H., \& Dodd, J. (2006). Truthmakers. Oxford: Oxford University Press.

Benacerraf, P. (1965). What numbers could not be. The Philosophical Review, 74, 47-73.

Bierwisch, M. (1987). Semantik der Graduierung. In M. Bierwisch \& E. Lang (Eds.), Grammatische und Konzeptuelle Aspekte von Dimensionsadjektiven (91-286). Berlin: Akademie Verlag.

Campbell, K. (1990). Abstract Particulars. Oxford: Blackwell.

Cresswell, M. (1976). The semantics of degrees. In B. Partee (Ed.), Montague grammar (261-292). New York: Academic Press.

Engel, R. E. (1989). On degrees. The Journal of Philosophy, 86, 23-37.

Fine, K. (1982). Acts, Events, and Things. In W. Leinfellner et al. (Eds.), Sprache und Ontologie. Proceedings of the eighth Wittgenstein symposium, Hoelder-Pichler-Tempsky, Vienna, pp. 97-105.

Fine, K. (1998). Cantorian abstraction: A reconstruction and defence. The Journal of Philosophy, 55(12), 599-634.

Goldman, A. (1971). A theory of human action. New York: Prentice Hall.

Heim, I. (2006). Remarks on comparative clauses as generalized quantifiers. Ms, MIT.

Kamp, H. (1975). Two theories of adjectives. In E. Keenan (Ed.), Formal semantics of natural language (123-155). Cambridge: Cambridge University Press.

Kennedy, C. (1999). Projecting the adjective: The syntax and semantics of gradability and comparison. New York: Garland.

Kennedy, C. (2001). Polar opposition and the ontology of degrees. Linguistics and Philosophy, 23, 33-70.

Kennedy, C. (2007). Vagueness and grammar. The semantics of relative and absolute gradable adjectives. Linguistics and Philosophy, 30, 1-45.

Klein, E. (1980). A Semantics for positive and comparative adjectives. Linguistics and Philosophy, 4, $1-45$.

Klein, E. (1991). Comparatives. In A. von Stechow \& D. Wunderlich (Eds.), Semantik: Ein Internationales Handbuch der Zeitgenoessischen Forschung (647-691). Berlin: Walter de Gruyter.

Levinson, J. (1980). The particularization of attributes. Australasian Journal of Philosophy, 58, 102-115.

Lowe, J. (2006). The four-category ontology. A metaphysical foundation for natural science. Oxford: Oxford University Press.

Maurin, A. -S. (2002). If Tropes. Dordrecht: Kluwer.

Mertz, D. W. (1996). Moderate realism and its logic. New Haven: Yale University Press.

Moltmann, F. (1997). Parts and wholes in semantics. Oxford: Oxford Universtiy Press.

Moltmann, F. (2004). Properties and kinds of tropes: New linguistic facts and old philosophical insights. Mind, 113, 1-43.

Moltmann, F. (2007). Events, tropes, and truthmaking. Philosophical Studies, 134, 343-403.

Morzycki, M. (2008). Adverbial modification of adjectives: Evaluatives and a little beyond. In J. Doelling et al. (Eds.), Event structure in linguistic form and interpretation. Berlin: de Gruyter.

Mulligan, K., Simons, P., \& Smith, B. (1984). Truthmakers. Philosophy and Phenomenological Research, 44, 287-321. 
Pinkal, M. (1989). On the logical structure of comparatives. In R. Studer (Ed.), Lecture notes in artificial intelligence, Berlin, pp. 146-167.

Reprinted in Mellor \& Oliver (Eds.), pp. 112-124.

Rizzi, L. (1999). Relativized minimality. Cambridge (Mass.): MIT Press.

Rothstein, S., \& Winter, Y. (2004). Total adjectives vs. partial adjectives: Scale structure and higher-order modifiers. Natural Language Semantics, 12, 259-288.

Schiffer, S. (1987). Remnants of meaning. Cambridge (Mass.): MIT Press

Schnieder, B. (2004). A note on particularized properties and bearer-uniqueness. Ratio, 17, 218-228.

Schwarzschild, R., \& Wilkinson, K. (2002). Quantifiers in comparatives. A semantics of degree based on intervals. Natural Language Semantics, 12, 1-41.

Schwarzschild, R. (2005). Measure phrases as modifiers of adjectives. Recherches linguistiques de vincennes, 35, 207-228.

Simons, P. (1994). Particulars in particular clothing. Three trope theories of substance. Philosophy and Phenomenological Research, 54(3), 553-574. Reprinted in S. Laurence \& C. MacDonald (Eds.), Contemporary readings in the foundations of metaphysics. Oxford: Blackwell, 1998.

Strawson, P. (1959). Individuals. London: Methuen.

Stout, G.F. (1952). God and nature. Cambridge: Cambridge University Press.

von Stechow, A. (1984). Comparing semantic theories of comparison. Journal of Semantics, 3, 1-77.

Williams, D. C. (1953). On the elements of being. The Review of Metaphysics, 7, 3-18.

Woltersdorff, N. (1970). On universals. Chicago: Chicago University Press.

Wright, C. (1983). Frege's conception of numbers as objects. Aberdeen: Aberdeen University Press.

Yoon, Y. (1996). Total and partial predicates and the weak-strong interpretations. Natural Language Semantics, 4, 217-236. 